\title{
Vaccine hesitancy among parents in Kuala Lumpur: a single
}

\section{center study [version 1; peer review: 2 approved with}

\section{reservations, 1 not approved]}

\author{
Ahmad Farouk Musa(D1, Trived Soni ${ }^{1}$, Xian Pei Cheong1', Rusli Bin Nordin (D)2 \\ 1Jeffrey Cheah School of Medicine and Health Sciences, Monash University Malaysia, Bandar Sunway, 47500 Selangor, Malaysia \\ ${ }^{2}$ School of Medicine, Faculty of Health and Medical Sciences, Taylor's University, Subang Jaya, 47500 Selangor, Malaysia
}

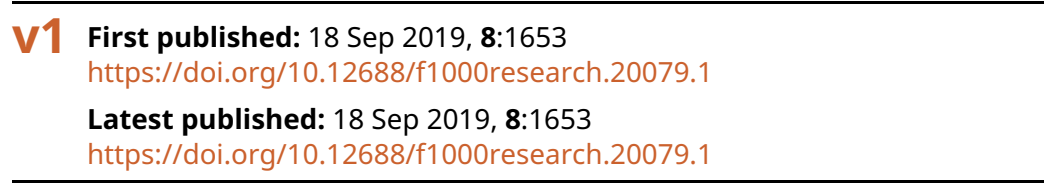

\section{Abstract}

Background: Vaccine hesitancy $(\mathrm{VH})$ is defined as the delay in acceptance or refusal of vaccination despite availability of vaccination services. The main objective of this study was to improve the understanding of vaccine hesitancy $(\mathrm{VH})$ among parents in Kuala Lumpur (KL), Malaysia, by determining the prevalence of $\mathrm{VH}$ among parents and to identify the predictors associated with a vaccine hesitant attitude.

Methods: This cross-sectional study was conducted in $\mathrm{KL}$. A questionnaire was devised to collect information from parents, namely sociodemographic information, WHO determinants of $\mathrm{VH}$ and the Parents Attitude towards Childhood Vaccine (PACV) scale.

Results: A total of 380 questionnaires were distributed and 337 were returned (88.6\% response rate). Those that completed 49 (>90\%) out of the 55 given questions in the survey were included for data analysis. Based on inclusion and exclusion criteria, 23 were excluded, giving a sample size of 314 . To identify parents, those with at least one child were included, giving a sample size of 221 . We noted $60.2 \%$ (189) of the participants were females and $80.3 \%$ (252) were Malay. Our study found a prevalence of $\mathrm{VH}$ of $14.5 \%$ among parents based on the 15-item PACV scale. Univariate analysis found no link between sociodemographic factors and $\mathrm{VH}$ in parents. Only five of these determinants were included in the final model as statistically significant $(p<0.05)$ predictors of $\mathrm{VH}$ among parents in $\mathrm{KL}$. The five factors were introduction to a new vaccine, negative past experiences of vaccinations, distrust of the pharmaceutical industry, distrust of health systems and providers and being male.

Conclusions: Factors contributing towards a prevalence of $\mathrm{VH}$ of $14.5 \%$ in $\mathrm{KL}$, Malaysia must be studied further to identify any temporal

\section{Open Peer Review \\ Approval Status $X ? ?$ 12 23 \\ version 1

$\underset{\text { view }}{\mathrm{X}}$ view $?$ 18Sep 2019 view view view \\ 1. Italo Francesco Angelillo, University of Campania "Luigi Vanvitelli", Naples, Italy \\ 2. Regina Célia de Menezes Succi, Universidade Federal de São Paulo (UNIFESP), São Paulo, Brazil \\ 3. Anju Aggarwal (D), University College of Medical Sciences and Guru Tegh Bahadur Hospital, New Delhi, India}

Any reports and responses or comments on the article can be found at the end of the article. 
relationship to the under-immunization of children in order to reach the WHO goal of $100 \%$ immunization coverage in children and eradication of vaccine preventable diseases.

\section{Keywords}

vaccine hesitancy, parental attitudes to childhood vaccine (PACV), prevalence, determinants

\section{Corresponding author: Ahmad Farouk Musa (farouk@monash.edu)}

Author roles: Musa AF: Conceptualization, Data Curation, Project Administration, Resources, Supervision, Validation, Visualization, Writing - Review \& Editing; Soni T: Formal Analysis, Investigation, Methodology, Software, Visualization, Writing - Original Draft Preparation; Cheong XP: Formal Analysis, Software, Validation, Visualization; Nordin RB: Data Curation, Formal Analysis, Project Administration, Supervision, Writing - Review \& Editing

Competing interests: No competing interests were disclosed.

Grant information: The author(s) declared that no grants were involved in supporting this work.

Copyright: (c) 2019 Musa AF et al. This is an open access article distributed under the terms of the Creative Commons Attribution License, which permits unrestricted use, distribution, and reproduction in any medium, provided the original work is properly cited.

How to cite this article: Musa AF, Soni T, Cheong XP and Nordin RB. Vaccine hesitancy among parents in Kuala Lumpur: a single center study [version 1; peer review: 2 approved with reservations, 1 not approved] F1000Research 2019, 8:1653

https://doi.org/10.12688/f1000research.20079.1

First published: 18 Sep 2019, 8:1653 https://doi.org/10.12688/f1000research.20079.1 


\section{Introduction}

Historically, it is said that Edward Jenner founded vaccine after he successfully inoculated a 13-year old boy with the cowpox virus, who then developed immunity against smallpox ${ }^{1,2}$. Since then, vaccination has come a long way, with multiple vaccines created for mass production and use.

Globally, it is found to be the single-most effective intervention to prevent infectious diseases worldwide. Beyond that, vaccines have also been said to prevent antibiotic resistance, empower women, protect against bioterrorism and extend life expectancy $^{3}$. In 2007, the British Medical Journal found vaccines to be one of four most important developments in medicine in the last 150 years, alongside sanitation, antibiotics and anesthesia ${ }^{4}$. Unfortunately, we are witnessing a huge rise in vaccine-preventable diseases (VPDs) in Malaysia, where there was an almost $1000 \%$ increase in the number of measles cases in 2018 compared to the previous year according to the Ministry of Health (MOH).

The devastating symptoms and fear of contracting certain diseases resulted in a great uptake of vaccines in their early years, resulting in the eradication of many vaccine-preventable diseases around the world. However, as time passed, more people have become vaccinated and sightings of these diseases have become rare. Thus, public attention has shifted from what was once a fear of a deadly disease to the possible risks and side effects of vaccination. The concerns and questions regarding vaccines gave rise to what we know today as vaccine hesitancy ( $\mathrm{VH})$.

VH can be appreciated from as early as the 1800 s, after the first vaccine was created by Edward Jenner. People complained about the invasiveness of methods used in administering vaccines. In addition to that, scientists questioned the basis for its efficacy, while religious groups rejected vaccination due to its unnatural ways and as an act of 'playing God's.

The epitome of vaccine controversy occurred at the end of the $19^{\text {th }}$ century, when Dr Andrew Wakefield published an article in The Lancet regarding the positive association between the measles, mumps and rubella (MMR) vaccine and bowel disease and autism ${ }^{6}$. This paper was formally retracted in view of Wakefield's conflict of interest, as well as committing scientific fraud by falsifying data. However, the influence of this report still lingers in many societies.

The World Health Organization (WHO) recently estimated that 19.4 million infants are missing out on basic vaccines, while one in five children worldwide do not receive routine life-saving vaccines ${ }^{7}$. Similarly, the United Nations International Children's Emergency Fund (UNICEF) has estimated that 2.7 million children die every year due to VPDs, of which $40 \%$ are from the Asian continent ${ }^{8}$. Furthermore, we are witnessing a similar trend in previously eradicated diseases, such as diphtheria and pertussis, which are once again infecting children in Malaysia.

\section{WHO determinants of $\mathrm{VH}$}

The term 'determinant of vaccination' includes the many dimensions and expressions of VH. The WHO's Strategic Advisory Group of Experts (SAGE) recognized the term 'determinants' as covering the topic of barriers and enablers of vaccination. After a review of models and discussion among experts regarding this topic, this working group recognized three categories of determinants of VH (Figure 1) 9 .

\section{Contextual influences}

Contextual influences consist of historic, environmental, economic, political, social, cultural and institutional factors that might influence VH populations ${ }^{10}$. Historically, the most famous incident is the relationship proposed between MMR and autism by Andrew Wakefield, published in The Lancet. The article gained interest and spread on many media sites, resulting in a decrease in MMR vaccination acceptance worldwide. Despite retracting this paper and disproving the theory in multiple follow up studies, parents still report concerns on safety of these vaccines ${ }^{11}$. In France, the national vaccination schedule was suspended in the 1990's due to a reported association between hepatitis B vaccination and multiple sclerosis ${ }^{12-15}$. Despite evidence disapproving the association, this belief remained in the community showing VH in small clusters of general practitioners ${ }^{16}$.

Unintentional suspicion may arise, especially when national policies are applicable to all and freedom of choice is not given to the public ${ }^{17}$. This distrust in the authorities and concerns regarding vaccine safety are sometimes shared among physicians as well ${ }^{16}$. Certain groups are commonly anti-vaccination, such as hard-liner naturopaths, professionals such as some groups of chiropractors, and some religious sects. The spreading of this belief by these groups can influence people to develop $\mathrm{VH}^{18-20}$. Some orthodox protestants believe that it is an act against God and any side effects are the consequence of Gods punishment ${ }^{21}$. Muslims require any consumed product to be Halal, and if vaccines are not branded Halal, they may be reluctant or refuse it altogether ${ }^{22,23}$.

In addition, the modern culture is such that the public questions the validity of science, especially when not backed by research evidence. Patient autonomy makes individuals easily influenced against vaccination, as they act based on their own knowledge and experiences in the past, which may not be updated or just be a misconception ${ }^{24}$.

\section{Individual and group influences}

Individual or group influences are influences arising from personal perception of the vaccines or influences of the social and peer environment ${ }^{10}$. The issue of vaccine safety is the most common determinant of VH. Vaccines are believed to be unsafe in terms of both short-term adverse reactions and long-term side effects. Nearly all the literature observes this reason for non-vaccination among VH groups ${ }^{9,25-28}$. Personal beliefs about the benefits of vaccines also influence vaccine uptake, with 


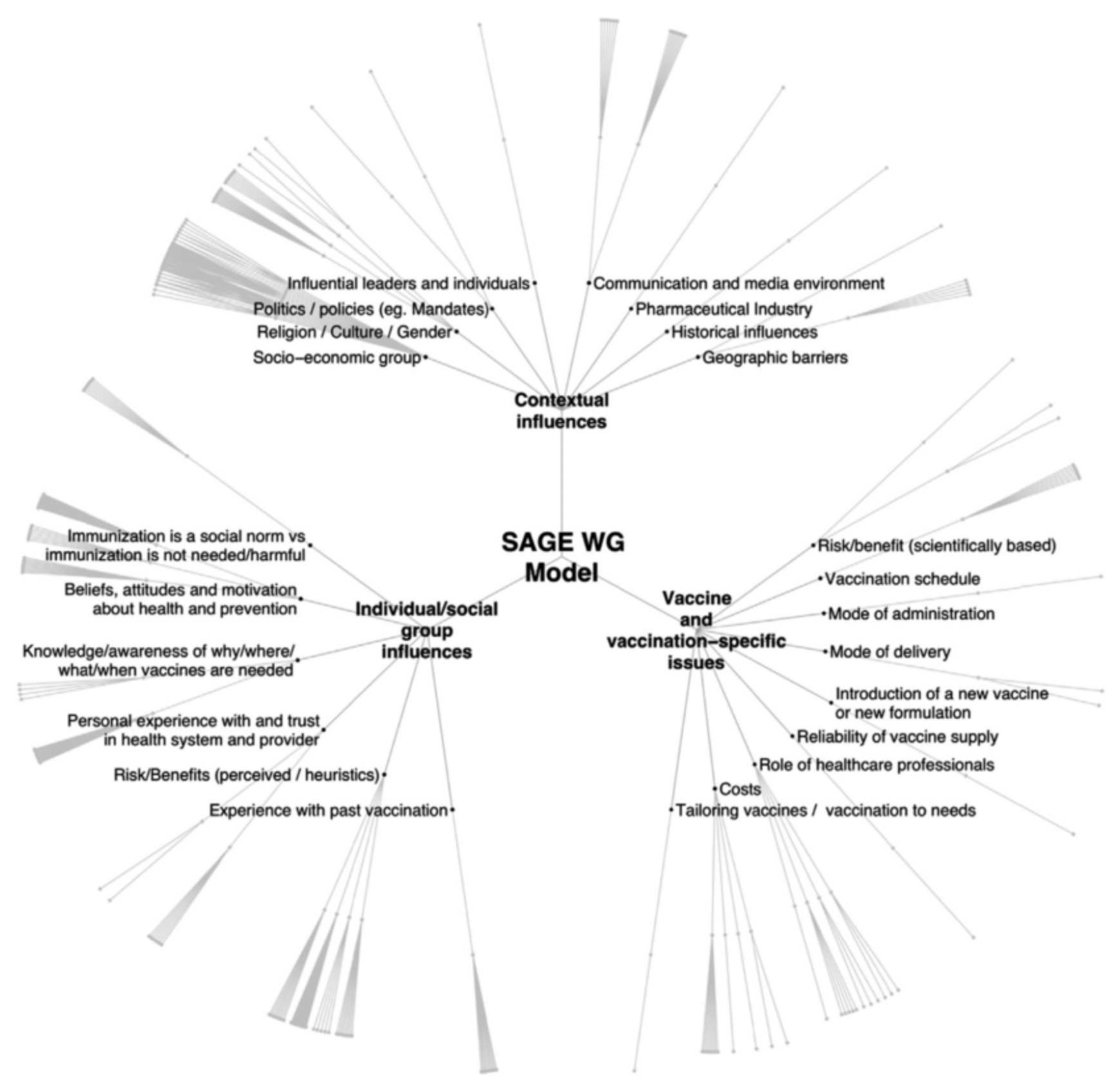

Figure 1. Strategic Advisory Group of Experts Working Group (SAGE WG) model of vaccine hesitancy. Reprinted from Vaccine; 32(19); Heidi J. Larson, Caitlin Jarrett, Elisabeth Eckersberger, David M.D. Smith, Pauline Paterson; Understanding vaccine hesitancy around vaccines and vaccination from a global perspective: A systematic review of published literature, 2007-2012; 2150-2159; Copyright (2014); ${ }^{25}$ with permission from Elsevier.

$67.6 \%$ of HPV non-vaccinees in the United States stating they consider it not at all or only somewhat beneficial ${ }^{29}$. Parents were found to be concerned about overwhelming their child's immune system and the risk of developing the disease after vaccination ${ }^{30}$. Interestingly, some physicians have doubts regarding the usefulness of certain vaccines themselves, and were therefore not recommending them; meningitis $\mathrm{C}$ and hepatitis $\mathrm{B}$ are examples $^{31,32}$.

The social norm has been found to be a positive reason for vaccine uptake ${ }^{33}$. Brown noted that having peers or relatives that were pro-MMR vaccine influenced vaccine uptake in the respondents ${ }^{34}$. In addition, viewing vaccination as a responsibility to society in terms of achieving herd immunity saw a higher vaccine uptake in a systematic review by Quadri-Sheriff ${ }^{35}$.

Risk perceptions influence vaccination decision ${ }^{36}$. From a lay person's point of view, risk is based on past experiences rather than evidenced-based medicine ${ }^{37,38}$. Besides that, weighing the risk of experiencing side effects with the risk of contracting the already rare VPDs plays a role in $\mathrm{VH}^{39}$. This is known as "omission bias'. The need for these vaccines then becomes questionable, 
as most commonly seen in human papillomavirus (HPV) vaccinations. Parents believe that their children are too young and presume that they are not sexually active; hence, do not require the vaccine ${ }^{40,41}$. Elderly females, on the other hand, claim that they are too old or no longer sexually active and don't need the vaccine $^{30,42}$.

\section{Vaccine and vaccine-specific issues}

Vaccines or vaccine-specific issues are directly or indirectly related to the $\mathrm{VH}$ attitude ${ }^{10}$. Every vaccine has its own production process and problems associated with it. Hence, it is subject to different degrees of hesitancy. There have been doubts about the reliability and constituents of specific vaccines such as thimerosal, albumin or aluminum-based additives ${ }^{43}$.

Most vaccines are expensive to produce, considering the amount of skilled lab work required. A survey found that half of pediatricians and family physicians surveyed in the United States had delayed purchase of specific vaccines in their practice due to cost (49\%) and experienced decreased profit margins for these vaccines $(53 \%)^{44,45}$. Fewer healthcare facilities providing vaccines may translate into poorer access for the public and hence, lower vaccination coverage. A similar problem is faced by patients, with higher prices being a barrier to vaccination. Those with private medical insurance show higher vaccination coverage than those without insurance ${ }^{43,46}$.

Another common reason for parents to not vaccinate their children is inconsistent advice from physicians. Interestingly, approximately 1 in 5 pediatricians dismiss families who refused one or more vaccines during their consultation. O'Leary discovered that these behaviors by physicians was related to the absence of philosophical exemption law and having a medium or difficult policy for attaining an exemption ${ }^{47}$. These physicians may feel overwhelmed by the concerns expressed by patients and it may jeopardize the doctor-patient relationship. This is alarming, as it is not only encouraging $\mathrm{VH}$ but repudiates access to healthcare for these patients. Others have found the complexity of the vaccine schedule and frequent updates to it very confusing. This then becomes a barrier, as physicians are not confident or comfortable discussing vaccination with parents ${ }^{48,49}$. The same applies to patients, who find the regimes too complicated to adhere to ${ }^{50}$.

\section{Aims and objectives}

The aim of this study was to improve our understanding of $\mathrm{VH}$ among parents in Malaysia, specifically looking at the Kuala Lumpur region. The objectives are as follows:

1. To determine the prevalence of $\mathrm{VH}$ among parents in Kuala Lumpur, Malaysia.

2. To identify predictors associated with a $\mathrm{VH}$ attitude in parents in Kuala Lumpur, Malaysia.

\section{Methods}

A cross-sectional research design was used for the purpose of this study, where sociodemographic and WHO determinants of $\mathrm{VH}$ were studied in relation to $\mathrm{VH}$ behavior in parents. This was the most suitable design, as it allowed us to demonstrate the relationship between multiple variables to the outcome at a point in time. The study was conducted from December 2016 to May 2017.

\section{Ethical statement}

Ethics clearance was obtained from the Monash University Human Research Ethics Committee (MUHREC: 9216) and the Medical Research Ethics Committee (MREC: NMRR-162508-33624[IIR]) of the Malaysian Ministry of Health before the commencement of the study.

\section{Sample size}

To calculate the required sample size for a single proportion, we used Pocock's formula: $\mathrm{n}=\mathrm{Z} \alpha^{2} \mathrm{P}(1-\mathrm{P}) / \mathrm{d}^{2}$, where $\mathrm{n}=$ minimum required sample size, $(Z \alpha)=1.96, d$ (precision) $=5 \%$, and $\mathrm{P}=$ expected prevalence. Based on our extensive literature search, the prevalence of $\mathrm{VH}$ was found to be within the range of $10 \%$ to $30 \%$. Using these percentages, respectively, an estimated sample size of between 138 and 318 was required. The average gave the required sample size of 227 . Considering potential dropouts and incomplete forms, $227+(20 \%)=275$ was our target sample size. A total of 380 questionnaires were distributed.

\section{Inclusion and exclusion criteria}

The specific inclusion criteria for a parent to participate in this study were as follows: aged 20 years or older; provided written consent; able to understand and comprehend English or Malay languages. The exclusion criteria were being too sick or in an uneasy state to complete questionnaire and being non-citizens of Malaysia.

\section{Participant recruitment}

Convenience sampling was adopted for recruiting patients from Tanglin Health Community Clinic, Kuala Lumpur. Patients were approached by the on-site investigator in the waiting area of the Maternity Clinic at Tanglin Health. All conversations and forms were given in either Malay or English language, depending on the preference of the participant. They were first asked if they would like to participate in a survey regarding $\mathrm{VH}$. Patients that were agreeable were then given a patient information sheet ${ }^{51}$ while the investigator briefly explained the purpose of the study and their role as participants. Eligible participants were given a separate consent form ${ }^{51}$ to obtain their signature and name as written consent. Once they had consented, they were handed the self-administered questionnaire, which was normally completed within 10-15 minutes and returned to the investigator.

\section{Questionnaire}

The questionnaire consisted of questions regarding sociodemographic characteristics and WHO determinants of $\mathrm{VH}$ (a copy of the questionnaire is available as Extended data ${ }^{51}$. While this questionnaire was not piloted or validated, it was based on SAGE Working Group on Vaccine Hesitancy's matrix of determinants of vaccine hesitancy and the PACV scale, which have been validated ${ }^{52,53}$. The matrix basically mapped out the key factors that influenced the decision to either accept, delay, or reject 
vaccination altogether. Three major domains were explored; namely, contextual, individual and group, and vaccine-specific.

\section{Data analysis}

All data computation was performed using the Statistical Package for Social Sciences (SPSS) version 23.0, provided by Monash University Malaysia. The data was initially checked for normality using the stem and leaf plot and the KolmogorovSmirnov test ( $p>0.05$ suggests normally distributed data).

Sociodemographic findings from the returned questionnaire were described using frequencies and percentages. For the prevalence and predictors of $\mathrm{VH}$ among parents, only participants who were parents were studied. This was determined using the inclusion criteria of having at least one child.

Findings from the second part (WHO determinants of $\mathrm{VH}$ ), that look into the three main domains were depicted as frequencies and percentages of 'YES' and 'NO' responses, except for questions one, two and three. All thirty-five questions were reviewed by a clinician in the field to determine right (non-hesitant) and wrong (hesitant) answers to score and ease analysis. From question four to 35, all 'NO' responses were hesitant responses, except for questions four, five, 11, 14, 21, 26, 30, 32, 33 and 35. For question one (source of information for vaccine) and two (reference when hearing negative comment about vaccine), participants were allowed to choose more than one answer. Overall, the response was portrayed in a bar chart. Responses for question one were subclassified into two or more sources (non-hesitant) compared to anything less than two sources (hesitant). As for question two, those who used a doctor as reference (non-hesitant) were compared to reference/consultation of all other groups (hesitant). For question three (which group that are anti-vaccine advocates are the most influential), participants were allowed to choose one answer only. Those that picked any of the choices were scored as hesitant, while the remainder who responded 'None' were scored as non-hesitant. All hesitant answers were scored as one and non-hesitant were scored as zero. For subdomains, the score of the questions were added up and the mean was used as the cut-off mark, where anything more than the mean was scored as one and anything less was scored as zero.

The outcome of $\mathrm{VH}$ in parents was determined by the Parent Attitudes about Childhood Vaccines (PACV) scale. The data obtained from the 221 parents were represented in a table using frequencies and percentages. The method and scoring used was according to the guidelines obtained from Opel ${ }^{26}$. The score given for each item was two for hesitant responses, one for unsure responses and zero for low/no hesitancy. For questions one and two, any 'Don't Know' (DK) responses were excluded as missing data in the analysis. The total score from the scale was divided by the maximum score (30) to calculate the percentage. Any score above $50 \%$ was classified as a vaccine hesitate parent (VHP), while scores below that were classified as no/low hesitancy to vaccines. In the case of missing values due to ' $\mathrm{DK}$ ' responses in questions one and two, the score was divided against the maximum adjusted score, where one 'DK' response $=28 \max$ score and two 'DK' responses $=26 \max$ score. Overall, the final scores for all respondents were used to determine the prevalence of $\mathrm{VH}$ among parents in percentage.

Sociodemographic factors and WHO determinants of VH were then examined for association with $\mathrm{VH}$ using chi square tests (Pearson Chi Square test, Fisher Exact test, and Mantel-Haenszel test for trend) with statistical significance set at $p<0.05$. Univariate binary logistic analysis for these variables was then carried out using odd ratios (ORs) and associated 95\% confidence intervals $(95 \% \mathrm{CIs})$ to determine significant predictors of $\mathrm{VH}$ among parents. From the analysis, all significant predictors $(p<0.05)$ were included in multivariate binary logistic regression using the stepwise method (backward logistic regression). The gave the final model, showing significant and independent predictors of $\mathrm{VH}$ in parents.

\section{Results}

Participation and inclusion in the study

A total of 380 questionnaires were distributed and 337 were returned (88.6\% response rate). Those that completed 49 (>90\%) out of the 55 given questions in the survey were included for further data analysis. For this reason, 22 participants were excluded, which gave a sample size of 314 . To identify parents for the $\mathrm{VH}$ in parents analysis, parents with at least one child were included, giving a sample size of 221.

\section{Sociodemographic characteristics}

A total of 314 questionnaires were included in the demographic data analysis ${ }^{51}$. Of these, 250 and 64 completed the Malay and English versions of the questionnaire, respectively. The ages of participants ranged from 20 to 80 years old. The most common age group was ' $30-39$ ' years followed by '20-29'. Figure 2 demonstrates the distribution of ages of the participants as a histogram. The average age of collected respondents were $39.25 \pm 13.033$ years.

As shown in Table 1, in terms of gender, 60.2\% (189) of the participants were female. There was a predominance of Malays $80.3 \%$ (252) compared to all other ethnic groups $19.7 \%$ (62). These other groups consisted of 31 Indian, 23 Chinese and eight other ethnicities. Likewise, Islam was the most common religion at $81.8 \%(257)$. Non-Muslims $(28.2 \%, 57)$ comprised of 25 Hindus, 18 Christians, 13 Buddhists, and one other.

The most common household income was the 'RM 2,000 - RM 5,000 ' category, reported by 143 respondents $(47.5 \%)$. Household incomes of '< RM 2,000' and 'RM 5,000 - RM 10,000' were reported by approximately $20 \%$ of the respondents for both groups.

In terms of education, there was a decreasing trend, with the highest proportion of participants completing secondary education (39.1\%), followed by a diploma $(34.3 \%)$. Only six participants had achieved the highest level of education; a doctorate.

Figure 3 shows the number of children of each participant. The average number of children for all the respondents were two children (mean=1.91) and 88 participants had no children. 


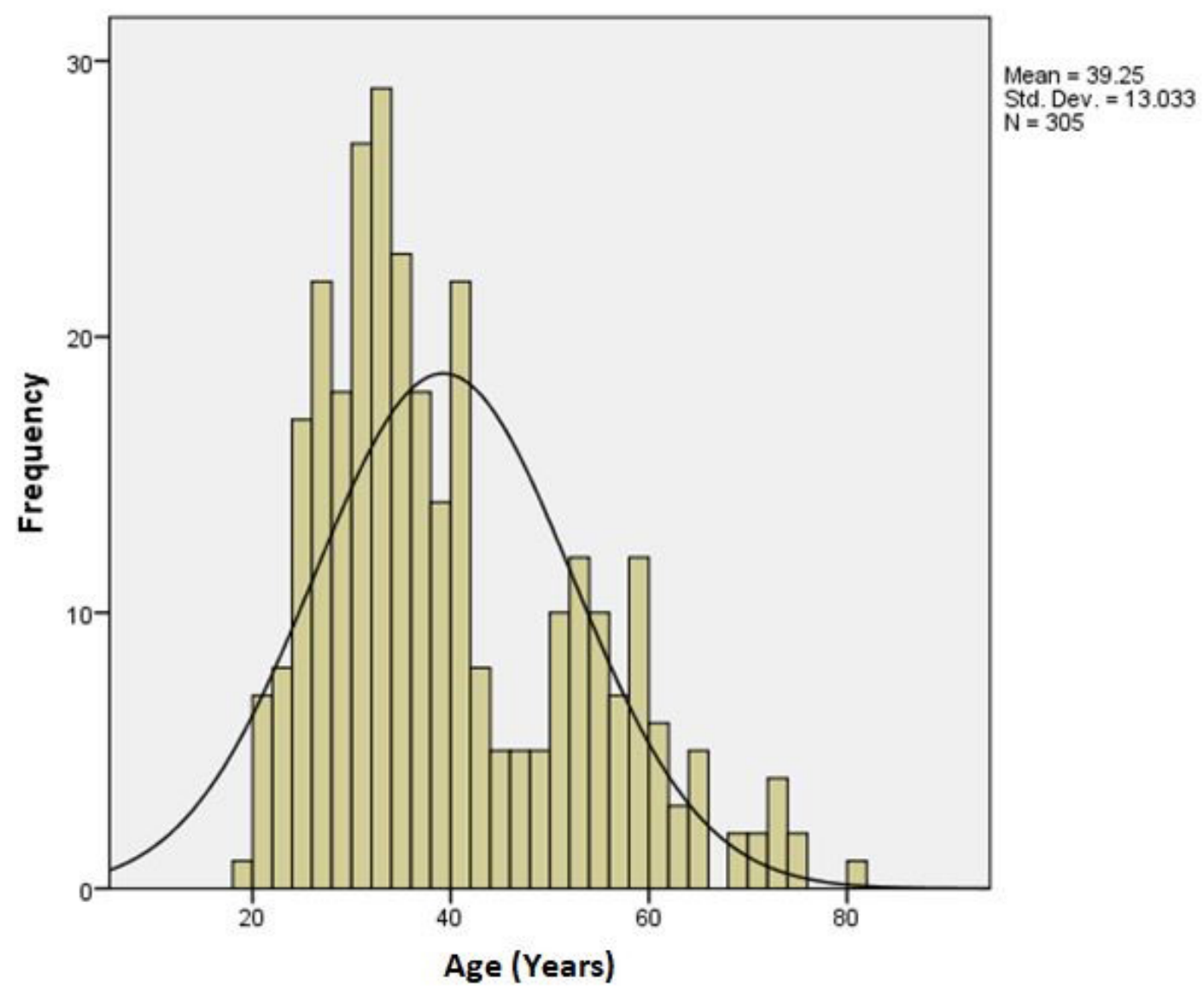

Figure 2. Representation of respondents' age.

Parents who had at least one child made up 221 of our respondents. This was further sub-divided into those with 'one or two children' and 'more than two children', with 119 and 102 respondents in these groups, respectively.

Finally, perceived immunization status showed that approximately $70 \%$ have had their children fully or partially immunized, while the remaining the $30 \%$ reported that their children had not been immunized at all. This perception was also seen in terms of self-vaccination status, in regard to HPV, influenza, the diphtheria, tetanus and pertussis booster and varicella vaccines.

\section{Contextual influences}

As shown in Figure 4, the majority of the respondents used television and the internet as their primary source of information regarding vaccines, reported by $50 \%$ and $52.2 \%$ of participants, respectively. Other utilized sources were newspapers $(34.1 \%)$ and social networking sites $(25.4 \%)$ such as Facebook. The use of radio or magazines as a source of information regarding vaccines was less common, with magazines being the least (11.5\%).

As illustrated in Figure 5, upon receiving negative information regarding vaccination, the majority of participants $(75.8 \%)$ acted by consulting doctors. The majority of the remaining participants referred to sources on the internet $(27.1 \%)$. A small number of participants consulted their colleagues or spouses about concerns related to unfavorable statements regarding vaccines. The group consulting religious leaders was reported by only $5.4 \%$ of participants.

Figure 6 shows that more than half $(61.3 \%)$ of respondents claimed to be unaware of any groups against vaccines. Amongst the known anti-vaccine groups, complementary/alternative medicine practitioners $(21.1 \%)$ were found to be most influential, followed closely by religious groups/leaders $(11.5 \%)$. On the other hand, traditional medicine and political group/leaders were less influential in exerting impact regarding anti-vaccination.

Referring to Table 2, a small number of participants (13.4\%) reported having negative experiences related to vaccination, which discourages them from permitting vaccination for their own children. We noticed that $23.2 \%$ of respondents reported having known or being acquainted with individuals who are hesitant towards vaccines due to religious beliefs. When asked their opinion, approximately $14.4 \%$ held the opinion that parents who refused vaccination for their children were not putting their life or their children's life at danger. From the questionnaire, the majority (92.6\%) expressed their assurance in the capabilities of the Ministry of Health (MOH) in making decisions regarding vaccinations. A similar number of participants agreed 
Table 1. Sociodemographic characteristics of participants.

\begin{tabular}{|c|c|c|c|}
\hline \multicolumn{2}{|c|}{ Sociodemographic characteristics } & \multirow[b]{2}{*}{$\begin{array}{l}\mathbf{n} \\
1 \\
72 \\
111 \\
45 \\
51 \\
25\end{array}$} & \multirow[b]{2}{*}{$\begin{array}{l}\% \\
0.3 \\
23.6 \\
36.4 \\
14.8 \\
16.7 \\
8.2\end{array}$} \\
\hline Age (year) & $\begin{array}{l}10-19 \\
20-29 \\
30-39 \\
40-49 \\
50-59 \\
\geq 60\end{array}$ & & \\
\hline Gender & $\begin{array}{l}\text { Male } \\
\text { Female }\end{array}$ & $\begin{array}{l}125 \\
189\end{array}$ & $\begin{array}{l}39.8 \\
60.2\end{array}$ \\
\hline Race & $\begin{array}{l}\text { Malay } \\
\text { Chinese } \\
\text { Indian } \\
\text { Other }\end{array}$ & $\begin{array}{l}252 \\
23 \\
31 \\
8\end{array}$ & $\begin{array}{l}80.3 \\
7.3 \\
9.9 \\
2.5\end{array}$ \\
\hline Religion & $\begin{array}{l}\text { Islam } \\
\text { Christianity } \\
\text { Buddhism } \\
\text { Hinduism } \\
\text { Other }\end{array}$ & $\begin{array}{l}257 \\
18 \\
13 \\
25 \\
1\end{array}$ & $\begin{array}{l}81.8 \\
5.7 \\
4.1 \\
8.0 \\
3\end{array}$ \\
\hline Household Income & $\begin{array}{l}<\text { RM2000 } \\
\text { RM2000 - RM5000 } \\
\text { RM5000 - RM10000 } \\
>\text { RM10000 }\end{array}$ & $\begin{array}{l}65 \\
143 \\
74 \\
19\end{array}$ & $\begin{array}{l}21.6 \\
47.5 \\
24.6 \\
6.3\end{array}$ \\
\hline Education Level & $\begin{array}{l}\text { Secondary Education } \\
\text { Diploma } \\
\text { Degree/Masters } \\
\text { Doctorate }\end{array}$ & $\begin{array}{l}122 \\
107 \\
77 \\
6\end{array}$ & $\begin{array}{l}39.1 \\
34.3 \\
24.7 \\
1.9\end{array}$ \\
\hline No. of Children & $\begin{array}{l}0 \\
1-2 \\
>2\end{array}$ & $\begin{array}{l}88 \\
119 \\
102\end{array}$ & $\begin{array}{l}28.5 \\
38.5 \\
33.0\end{array}$ \\
\hline Child Immunization Status & $\begin{array}{l}\text { None at all } \\
\text { Partial } \\
\text { Full }\end{array}$ & $\begin{array}{l}86 \\
19 \\
203\end{array}$ & $\begin{array}{l}27.9 \\
6.2 \\
65.9\end{array}$ \\
\hline Self-Immunization Status & $\begin{array}{l}\text { None at all } \\
\text { Partial } \\
\text { Full }\end{array}$ & $\begin{array}{l}98 \\
98 \\
107\end{array}$ & $\begin{array}{l}32.3 \\
32.3 \\
35.3\end{array}$ \\
\hline
\end{tabular}

that vaccination should be made compulsory. Likewise, $12.3 \%$ of respondents would forgo vaccination for their children if it required a commute of more than an hour. A lower but still a sizable percentage of participants $(83.0 \%)$ trusted the safety and effectiveness of vaccines produced by pharmaceutical companies.

\section{Group/individual influences}

Referring to Table 3, 41 participants $(13.1 \%)$ claimed to know of people who had experienced severe side effects following vaccination. Roughly two thirds (65.5\%) of the respondents denied knowing of cases in which unvaccinated children had suffered from illness because they were not vaccinated. Only 23 participants $(7.4 \%)$ held the belief that vaccines do not boost the body's immune response. Alarmingly, a large proportion of participants $(38.9 \%)$ believed that there are superior alternatives to vaccines in preventing illness. When asked about their knowledge of vaccines, $40.8 \%$ admitted they were ignorant on which vaccines were suitable for them or their children. In fact, about half of the participants $(49.5 \%)$ had not heard of the HPV vaccination prior to taking the survey. A small proportion, but not an insignificant one, of $12.7 \%$ believed that polio vaccines were redundant and no longer required.

\section{Vaccines/vaccine specific issues}

As shown in Table 4, most participants believed that vaccines are safe for them or their children. However, $45.6 \%$ of participants responded that they did not receive sufficient information regarding vaccines and their safety and $55.7 \%$ indicated their reluctance in letting their child be the first recipient of a new vaccine. With regard to the method of administering the vaccine, $40.5 \%$ of participants indicated a preference for methods other than injection. The process of vaccination was found to be simple and easy with most participants being confident that the clinics/hospital they visit are well equipped with the vaccines they require. A total of $57.6 \%$ of participants are unaware of the MOH'S vaccination schedule and $37.5 \%$ of respondents believed that some vaccines were difficult to obtain due to the vaccine schedules. Despite that, the vast majority $(93.5 \%)$ believed that 


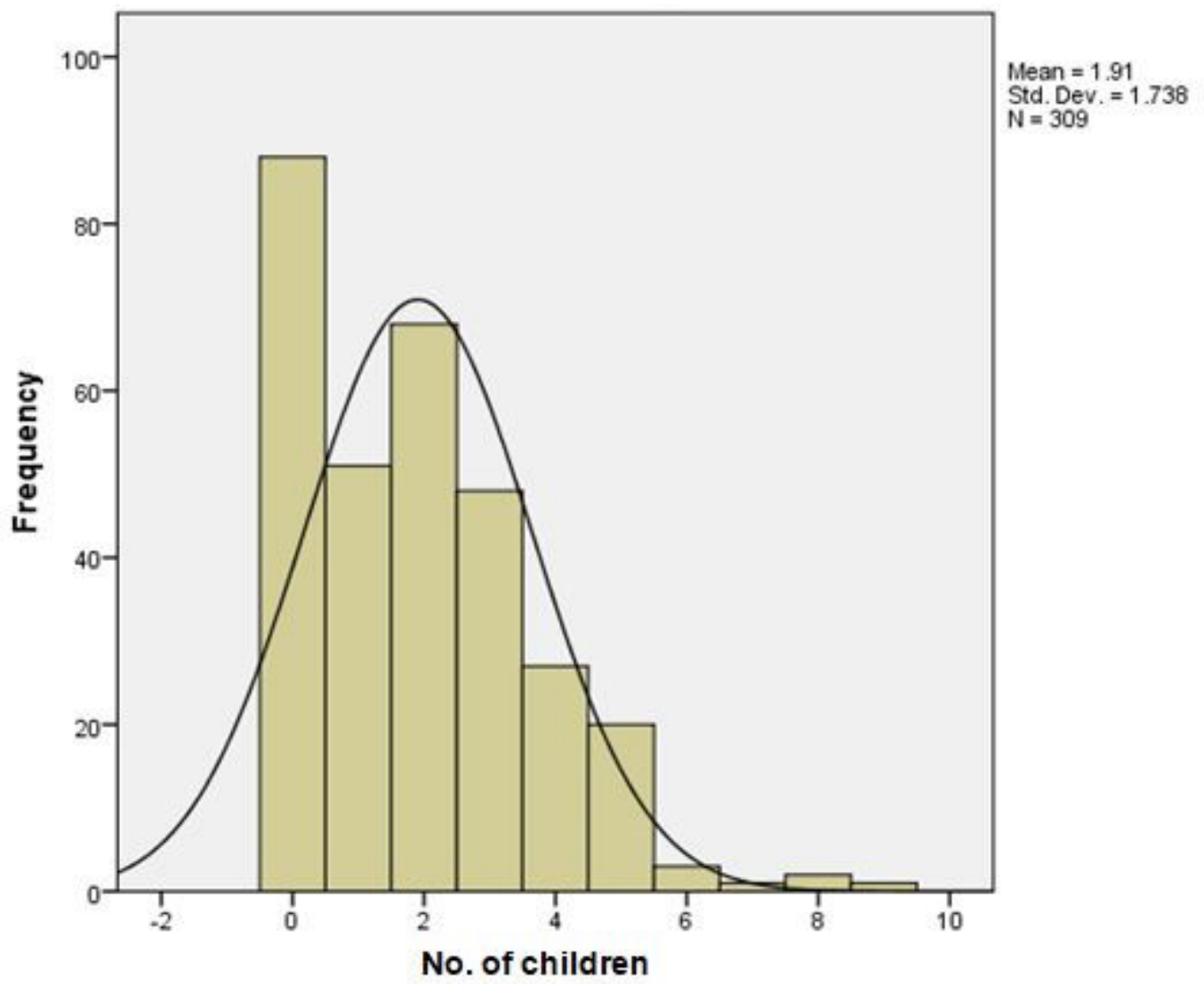

Figure 3. Representation of number of children of respondents.

\section{Main Source of Information for Vaccination}

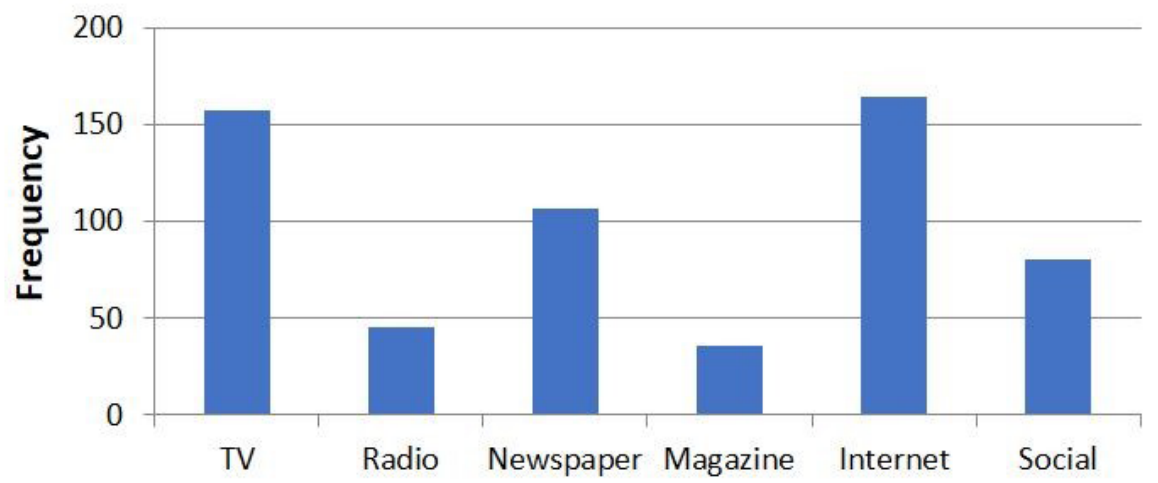

Figure 4. Parents source of information to vaccine/vaccinations. 


\section{Reference / Consult when hearing a negative comment about vaccination}

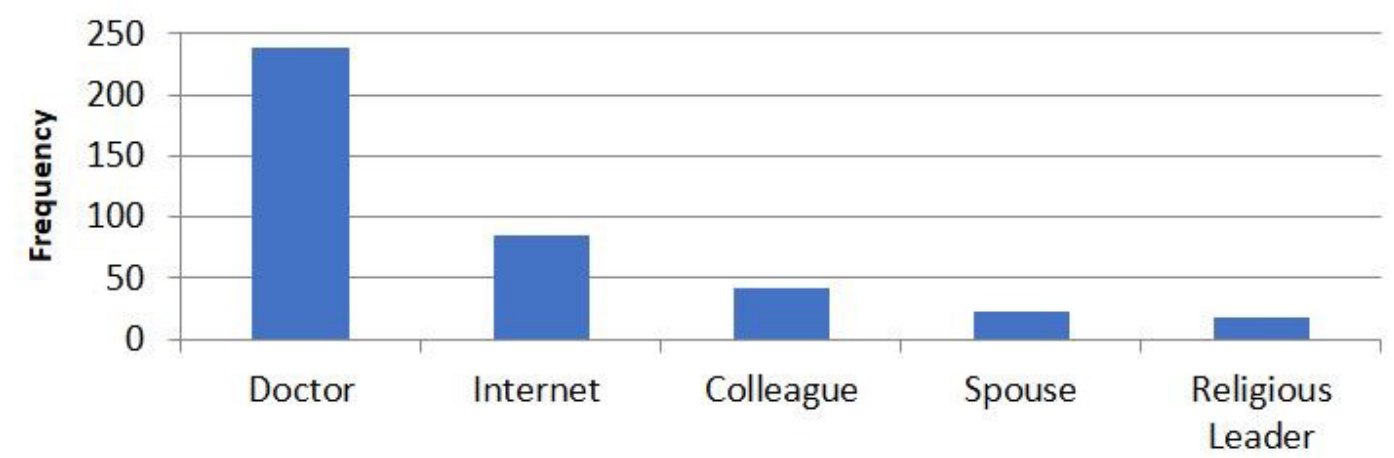

Figure 5. Reference/Consultation group of parents when hearing a negative comment about vaccine/vaccinations.

\section{Most influential groups that advocate anti-vaccine}

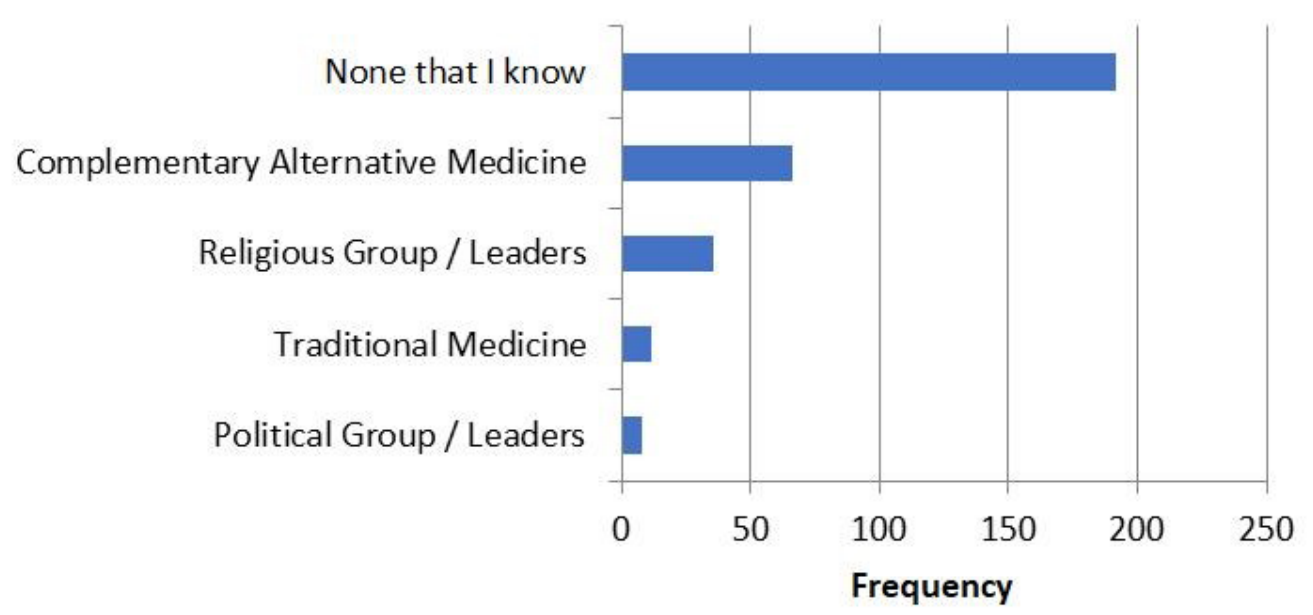

Figure 6. Parents response to who they think are most influential anti-vaccine advocate groups. 
Table 2. Response of parents in contextual influences regarding vaccine hesitancy.

\begin{tabular}{|c|c|c|}
\hline Question & Yes (\%) & No (\%) \\
\hline \multicolumn{3}{|l|}{ Historical Influence } \\
\hline 4. Do you remember any event in the past that discourages you or your child from getting vaccinated? & $41(13.4)$ & $266(86.6)$ \\
\hline \multicolumn{3}{|l|}{ Religious Belief } \\
\hline 5. Do you know anyone who rejects vaccination because of his/her religious beliefs? & $72(23.2)$ & $239(76.8)$ \\
\hline $\begin{array}{l}\text { 6. Do you think that they are taking risks to their health and those of their children if they refuse } \\
\text { vaccination? }\end{array}$ & $262(85.6)$ & $44(14.4)$ \\
\hline \multicolumn{3}{|l|}{ Politics } \\
\hline 7. Are you confident with the Ministry of Health $(\mathrm{MoH})$ making decisions for you regarding vaccination? & $287(92.6)$ & $23(7.4)$ \\
\hline 8. Do you think that vaccination should be made compulsory? & $271(89.4)$ & $32(10.6)$ \\
\hline \multicolumn{3}{|l|}{ Geographical Barriers } \\
\hline $\begin{array}{l}\text { 9. If you have to spend more than an hour journey to get a vaccine, will you proceed to get the } \\
\text { vaccination for you or your child? }\end{array}$ & $270(87.7)$ & 38 (12.3) \\
\hline \multicolumn{3}{|l|}{ Pharmaceutical Industries } \\
\hline $\begin{array}{l}\text { 10. Do you trust pharmaceutical companies manufacture vaccines that are safe and effective for your } \\
\text { health? }\end{array}$ & $254(83.0)$ & $52(17.0)$ \\
\hline
\end{tabular}

All hesitant answers are 'NO' except for questions four and five.

Table 3. Response of parents for individual/group influences regarding vaccines.

\begin{tabular}{|c|c|c|}
\hline Question & Yes (\%) & No (\%) \\
\hline \multicolumn{3}{|l|}{ Past Experience } \\
\hline 11. Do you know of anyone experiencing severe side effects of vaccines? & $41(13.1)$ & $272(86.9)$ \\
\hline 12. Do you know of any children suffering from illnesses because they are not vaccinated? & $108(34.5)$ & $205(65.5)$ \\
\hline \multicolumn{3}{|l|}{ Belief and Attitudes } \\
\hline 13. Do you believe that vaccines do not strengthen the body's immune responses? & $288(92.6)$ & $23(7.4)$ \\
\hline 14. Do you feel that there are better ways to prevent illnesses that are currently prevented by vaccines? & $119(38.9)$ & $187(61.1)$ \\
\hline \multicolumn{3}{|l|}{ Knowledge and Awareness } \\
\hline 15. Do you feel that you know of suitable vaccines for you or your children? & $184(59.2)$ & $127(40.8)$ \\
\hline 16. Have you ever heard of the HPV vaccine? & $153(49.5)$ & $156(50.5)$ \\
\hline 17. Do you feel that the polio vaccine is still needed? & $261(87.3)$ & $38(12.7)$ \\
\hline \multicolumn{3}{|l|}{ Health System and Providers Trust } \\
\hline $\begin{array}{l}\text { 18. Are you satisfied with the advice and explanations of your doctor in relation to your questions on } \\
\text { immunization? }\end{array}$ & $274(88.4)$ & $36(11.6)$ \\
\hline 19. Do you feel that your health provider is concerned about what is good for you and your children? & $271(87.4)$ & $39(12.6)$ \\
\hline \multicolumn{3}{|l|}{ Perceived Risk/Benefit } \\
\hline 20. Do you believe that vaccines can prevent illnesses from becoming serious? & $294(94.2)$ & $18(5.8)$ \\
\hline 21. Do you have any worries about vaccines? & $85(27.4)$ & $225(72.6)$ \\
\hline \multicolumn{3}{|l|}{ Immunization as a social norm } \\
\hline 22. Do you feel that it is important for every individual to ensure that his/her child is immunized? & $298(96.1)$ & $12(3.9)$ \\
\hline
\end{tabular}

All hesitant answers are 'NO' except for questions 11, 14 and 21. 
Table 4. Parents response to vaccine/vaccine specific issues in regards to vaccines.

\begin{tabular}{|c|c|c|}
\hline Question & Yes (\%) & No (\%) \\
\hline \multicolumn{3}{|l|}{ Evidence based risk/benefit } \\
\hline 23. Do you feel that vaccines are safe for you or your child? & $295(95.8)$ & $13(4.2)$ \\
\hline 24. Do you get enough information about vaccines and their safety? & $167(54.4)$ & $140(45.6)$ \\
\hline \multicolumn{3}{|l|}{ Introduction to a new vaccine } \\
\hline 25. When a new vaccine is introduced, do you want your child to be the first recipient of the vaccine? & $131(42.8)$ & $175(55.7)$ \\
\hline \multicolumn{3}{|l|}{ Mode of Administration } \\
\hline $\begin{array}{l}\text { 26. Do you have any preferences as to the administration of vaccines other than injection? (nasal spray, } \\
\text { pill, patch, syrup) }\end{array}$ & $138(45.0)$ & $169(55.0)$ \\
\hline \multicolumn{3}{|l|}{ Vaccination process and availability } \\
\hline 27. Is the immunization process simple and easy? & $280(91.5)$ & $26(8.5)$ \\
\hline $\begin{array}{l}\text { 28. Are you confident that the clinics/hospitals will have available vaccines for your children, when they } \\
\text { are needed? }\end{array}$ & $291(94.2)$ & $18(5.8)$ \\
\hline \multicolumn{3}{|l|}{ Vaccination Schedule } \\
\hline 29. Do you know of the recommended MoH's vaccination schedule? & $131(42.4)$ & $178(57.6)$ \\
\hline 30. Are there vaccines that are difficult to obtain because of the vaccination schedules? & $113(37.5)$ & $188(62.5)$ \\
\hline 31. Do you believe that vaccines must be taken according to the schedules? & $289(93.5)$ & $20(6.5)$ \\
\hline \multicolumn{3}{|l|}{ Cost } \\
\hline $\begin{array}{l}\text { 32. Do you feel that ever since vaccines for your children are given free, these vaccines must be useless } \\
\text { or of no value? }\end{array}$ & $23(7.3)$ & $286(92.3)$ \\
\hline 33. Are you willing to personally pay for vaccines? & $201(65.9)$ & $104(34.1)$ \\
\hline \multicolumn{3}{|l|}{ Duty of healthcare provider } \\
\hline $\begin{array}{l}\text { 34. Have you or your child ever been rudely mistreated so much so that you are hesitant about returning } \\
\text { to the healthcare provider? }\end{array}$ & $39(12.6)$ & $271(87.4)$ \\
\hline 35. Have your healthcare provider ever advised you that a certain vaccine is not needed? & $83(26.9)$ & $225(73.1)$ \\
\hline
\end{tabular}

All hesitant answers are 'NO' except for questions 26, 30, 32, 34 and 35.

vaccines should be taken according to schedules. Nearly all participants believed vaccines had a significant value despite being administered to children for free. However, when asked about their willingness to bear the cost of vaccines, $34.1 \%$ replied negatively. Furthermore, $12.6 \%$ of participants were reluctant on returning to a healthcare provider due to mistreatment and $26.9 \%$ claimed to have received advice from a healthcare provider that a certain vaccine was not required.

VHPS

Our study shows a prevalence of VH of $14.5 \%$ (32/221 patients) among parents, based on the 15-item Parental Attitudes to Childhood Vaccine (PACV) scale (Table 5). Hesitancy was calculated based on Opel $^{26}$ scoring (see Methods).

Table 6 demonstrates the responses received from 221 parents on the PACV scale. A total of $18.1 \%$ of parents have postponed vaccination due to reasons other than illness or allergy. Of these, only $9.0 \%$ didn't get these vaccines at all. Most parents were confident of the $\mathrm{MOH}$ childhood vaccination schedule. However, nearly half of the respondents thought that children
Table 5. Prevalence of vaccine hesitancy among 221 patients.

\begin{tabular}{|l|l|l|}
\hline Hesitancy status & Frequency (n) & Percent (\%) \\
\hline Non-hesitant parents & 185 & 83.7 \\
\hline Hesitant parents & 32 & 14.5 \\
\hline Incomplete data & 4 & 1.8 \\
\hline Total & 221 & 100 \\
\hline
\end{tabular}

get too many vaccinations than are needed and were concerned about the safety and side effects of vaccines.

At least a third of parents agreed that it is better for children to develop natural immunity by getting sick rather than being vaccinated and it is better for children to receive fewer vaccine shots simultaneously. We also noted that $30.3 \%$ of parents were concerned about the efficacy of vaccines in preventing illness. Only $2.7 \%$ responded that if they had another infant, 


\section{Table 6. Parents attitude towards childhood vaccine findings from 221 parents.}

\begin{tabular}{|c|c|c|c|c|}
\hline No. & Item & Response & Frequency (n) & Percent (\%) \\
\hline 1 & $\begin{array}{l}\text { Have you ever postponed vaccination because of reasons other than } \\
\text { illness or allergy? }\end{array}$ & $\begin{array}{l}\text { No } \\
\text { Yes } \\
\text { Don't Know }\end{array}$ & $\begin{array}{l}173 \\
40 \\
8\end{array}$ & $\begin{array}{l}78.3 \\
18.1 \\
3.6\end{array}$ \\
\hline 2 & $\begin{array}{l}\text { Have you ever rejected vaccination because of reasons other than illness } \\
\text { or allergy? }\end{array}$ & $\begin{array}{l}\text { No } \\
\text { Yes } \\
\text { Don't Know }\end{array}$ & $\begin{array}{l}195 \\
20 \\
6\end{array}$ & $\begin{array}{l}88.2 \\
9.0 \\
2.7\end{array}$ \\
\hline 3 & $\begin{array}{l}\text { How confident are you of the vaccination schedule of the Ministry of } \\
\text { Health }(\mathrm{MoH}) \text { ? }\end{array}$ & $\begin{array}{l}8-10 \\
6-7 \\
0-5\end{array}$ & $\begin{array}{l}195 \\
7 \\
19\end{array}$ & $\begin{array}{l}88.2 \\
3.2 \\
8.6\end{array}$ \\
\hline 4 & Children get too much vaccination than are needed. & $\begin{array}{l}\text { Disagree } \\
\text { Not Sure } \\
\text { Agree }\end{array}$ & $\begin{array}{l}81 \\
34 \\
106\end{array}$ & $\begin{array}{l}36.7 \\
15.3 \\
48.0\end{array}$ \\
\hline 5 & I believe that vaccination is necessary to prevent serious illnesses. & $\begin{array}{l}\text { Disagree } \\
\text { Not Sure } \\
\text { Agree } \\
\text { Unfilled }\end{array}$ & $\begin{array}{l}83 \\
37 \\
100 \\
1\end{array}$ & $\begin{array}{l}37.6 \\
16.7 \\
45.2 \\
0.5\end{array}$ \\
\hline 6 & $\begin{array}{l}\text { It is better for me or my children to strengthen our bodies' immune system } \\
\text { by naturally getting sick rather than being vaccinated }\end{array}$ & $\begin{array}{l}\text { Disagree } \\
\text { Not Sure } \\
\text { Agree } \\
\text { Unfilled }\end{array}$ & $\begin{array}{l}77 \\
55 \\
88 \\
1\end{array}$ & $\begin{array}{l}34.8 \\
24.9 \\
39.8 \\
0.5\end{array}$ \\
\hline 7 & $\begin{array}{l}\text { It is better for me or my children to receive less vaccination at the same } \\
\text { time }\end{array}$ & $\begin{array}{l}\text { Disagree } \\
\text { Not Sure } \\
\text { Agree }\end{array}$ & $\begin{array}{l}54 \\
58 \\
109\end{array}$ & $\begin{array}{l}24.4 \\
26.3 \\
49.3\end{array}$ \\
\hline 8 & $\begin{array}{l}\text { How worried are you that you or your child may develop serious side } \\
\text { effects of vaccination? }\end{array}$ & $\begin{array}{l}\text { Not concerned } \\
\text { Not sure } \\
\text { Concerned }\end{array}$ & $\begin{array}{l}211 \\
6 \\
4\end{array}$ & $\begin{array}{l}95.5 \\
2.7 \\
1.8\end{array}$ \\
\hline 9 & How worried are you that any of the vaccines might not be safe? & $\begin{array}{l}\text { Not concerned } \\
\text { Not sure } \\
\text { Concerned }\end{array}$ & $\begin{array}{l}72 \\
67 \\
82\end{array}$ & $\begin{array}{l}32.6 \\
30.3 \\
37.1\end{array}$ \\
\hline 10 & How worried are you that vaccination is not effective to prevent an illness? & $\begin{array}{l}\text { Not concerned } \\
\text { Not sure } \\
\text { Concerned }\end{array}$ & $\begin{array}{l}69 \\
85 \\
67\end{array}$ & $\begin{array}{l}31.2 \\
38.5 \\
30.3\end{array}$ \\
\hline 11 & $\begin{array}{l}\text { If you have an infant now, do you want the infant to receive all } \\
\text { vaccinations as suggested? }\end{array}$ & $\begin{array}{l}\text { Yes } \\
\text { Don't Know } \\
\text { No } \\
\text { Unfilled }\end{array}$ & $\begin{array}{l}180 \\
34 \\
6 \\
1\end{array}$ & $\begin{array}{l}81.4 \\
15.4 \\
2.7 \\
0.5\end{array}$ \\
\hline 12 & In general, to what extent are you hesitant about children's vaccination? & $\begin{array}{l}\text { Non-hesitant } \\
\text { Not sure } \\
\text { Hesitant } \\
\text { Unfilled }\end{array}$ & $\begin{array}{l}193 \\
18 \\
8 \\
2\end{array}$ & $\begin{array}{l}87.3 \\
8.2 \\
3.6 \\
0.9\end{array}$ \\
\hline 13 & I trust the information that I receive about vaccinations. & $\begin{array}{l}\text { Agree } \\
\text { Not sure } \\
\text { Disagree } \\
\text { Unfilled }\end{array}$ & $\begin{array}{l}144 \\
29 \\
47 \\
1\end{array}$ & $\begin{array}{l}65.2 \\
13.1 \\
21.3 \\
0.5\end{array}$ \\
\hline 14 & I can discuss my concerns of vaccination with my child's doctor. & $\begin{array}{l}\text { Agree } \\
\text { Not sure } \\
\text { Disagree } \\
\text { Unfilled }\end{array}$ & $\begin{array}{l}145 \\
39 \\
34 \\
3\end{array}$ & $\begin{array}{l}65.6 \\
17.6 \\
15.4 \\
1.4\end{array}$ \\
\hline 15 & $\begin{array}{l}\text { Taking everything into consideration, how confident are you of your child's } \\
\text { doctor? }\end{array}$ & $\begin{array}{l}8-10 \\
6-7 \\
0-5 \\
\text { Unfilled }\end{array}$ & $\begin{array}{l}158 \\
33 \\
28 \\
2\end{array}$ & $\begin{array}{l}71.5 \\
14.9 \\
12.7 \\
0.9\end{array}$ \\
\hline
\end{tabular}


they would not want them to receive all the recommended vaccinations and $3.6 \%$ responded that they were hesitant about vaccinations. Furthermore, only $12.7 \%$ of parents were not confident in their child's doctor.

\section{Univariate analysis predicting $\mathrm{VH}$ among parents}

Table 7 shows the findings of univariate binary logistic regression of all the factors studied in regard to VHP. In terms of sociodemographic characteristics, it was found that male parents are most likely to be $\mathrm{VH}$ as compared to female parents (OR $2.431, p=0.022,95 \%$ CI 1.135-5.204). Other factors such as age, income, education status and number of children did not show any association to hesitancy in our study.

For contextual influence, there was no association for the number of sources of information or consulting anyone other than

Table 7. Univariate analysis predicting vaccine hesitancy among parents.

\begin{tabular}{|c|c|c|c|c|c|c|c|c|c|}
\hline \multicolumn{8}{|c|}{ Predictor of vaccine hesitancy } & \multicolumn{2}{|c|}{$95 \% \mathrm{Cl}$ for $\operatorname{Exp}(\mathrm{B})$} \\
\hline \multicolumn{2}{|c|}{ Sociodemographics } & B & S.E. & Wald & df & Sig. & $\operatorname{Exp}(B)$ & Lower & Upper \\
\hline Age & Age & .008 & .015 & .286 & 1 & .593 & 1.008 & .979 & 1.038 \\
\hline Gender & Male & .888 & .388 & 5.229 & 1 & .022 & 2.431 & 1.135 & 5.204 \\
\hline \multirow[t]{4}{*}{ Income } & Less than RM2000 & & & 5.389 & 3 & .145 & & & \\
\hline & RM2000 - RM4999 & -.405 & .748 & .294 & 1 & .588 & 1.500 & .346 & 6.501 \\
\hline & RM4999 - RM10000 & -.791 & .730 & 1.173 & 1 & .279 & .453 & .108 & 1.897 \\
\hline & $>$ RM10000 & -.201 & .727 & .077 & 1 & .782 & .818 & .197 & 3.402 \\
\hline \multirow[t]{4}{*}{ Education } & Secondary & & & .630 & 3 & .889 & & & \\
\hline & Diploma & -.536 & 1.160 & .213 & 1 & .644 & .585 & .060 & 5.686 \\
\hline & Degree & -.318 & 1.170 & .074 & 1 & .727 & .727 & .073 & 7.200 \\
\hline & Doctorate & -.201 & 1.176 & .029 & 1 & .818 & .818 & .082 & 8.207 \\
\hline No. of children & 1-2 children & .413 & .394 & 1.103 & 1 & .294 & 1.512 & .699 & 3.271 \\
\hline \multicolumn{10}{|c|}{ Contextual Influence } \\
\hline \multicolumn{2}{|c|}{ 1. Historical influence } & -.474 & .477 & .986 & 1 & .321 & .623 & .245 & 1.586 \\
\hline \multicolumn{2}{|c|}{ 2. Religious belief } & -.321 & .420 & .583 & 1 & .445 & .726 & .319 & 1.652 \\
\hline \multicolumn{2}{|c|}{ 3. Healthcare Policies } & 2.325 & .552 & 17.716 & 1 & .000 & 10.23 & 3.464 & 30.197 \\
\hline \multicolumn{2}{|c|}{ 4. Geographical barrier } & 1.486 & .477 & 9.716 & 1 & .002 & 4.420 & 1.736 & 11.251 \\
\hline \multicolumn{2}{|c|}{ 5. Trust in pharmaceutical industries } & 2.331 & .442 & 27.77 & 1 & .000 & 10.29 & 4.322 & 24.476 \\
\hline \multicolumn{10}{|c|}{ Individual / group influence } \\
\hline \multicolumn{2}{|c|}{ 1. Past experience } & -1.313 & .449 & 8.568 & 1 & .003 & .269 & .112 & .648 \\
\hline \multicolumn{2}{|c|}{ 2. Beliefs \& Attitudes } & 1.247 & .588 & 4.498 & 1 & .034 & 3.480 & 1.099 & 11.018 \\
\hline \multicolumn{2}{|c|}{ 3. Knowledge \& Awareness } & 1.113 & .409 & 7.414 & 1 & .006 & 3.042 & 1.366 & 6.776 \\
\hline \multicolumn{2}{|c|}{ 4. Trust in Health System \& Provider } & 2.394 & .474 & 25.491 & 1 & .000 & 10.96 & 4.327 & 27.766 \\
\hline \multicolumn{2}{|c|}{ 5. Perception of Risk \& Benefit } & 2.206 & .599 & 13.572 & 1 & .000 & 9.080 & 2.808 & 29.362 \\
\hline \multicolumn{2}{|l|}{ 6. Social Norm } & 2.639 & .891 & 8.772 & 1 & .003 & 14.00 & 2.442 & 80.276 \\
\hline \multicolumn{10}{|c|}{ Vaccine/Vaccination specific issues } \\
\hline \multicolumn{2}{|c|}{ 1. Scientific evidence to risk and benefit } & 2.905 & .725 & 16.065 & 1 & .000 & 18.26 & 4.412 & 75.580 \\
\hline \multicolumn{2}{|c|}{ 2. Introduction to a new vaccine } & 2.127 & .627 & 11.489 & 1 & .001 & 8.387 & 2.452 & 28.686 \\
\hline \multicolumn{2}{|c|}{ 3. Mode of administration of vaccine } & -.424 & .395 & 1.149 & 1 & .284 & .655 & .302 & 1.421 \\
\hline \multicolumn{2}{|c|}{ 4. Design of vaccine and procedure } & 2.381 & .530 & 20.186 & 1 & .000 & 10.81 & 3.827 & 30.547 \\
\hline \multicolumn{2}{|c|}{ 5. Vaccine schedule } & .987 & .415 & 5.662 & 1 & .017 & 2.684 & 1.190 & 6.051 \\
\hline \multicolumn{2}{|c|}{ 6. Cost of vaccine } & 1.208 & .406 & 8.864 & 1 & .003 & 3.347 & 1.511 & 7.418 \\
\hline \multicolumn{2}{|c|}{ 7. Role of healthcare professionals } & -1.655 & .486 & 11.610 & 1 & .001 & .191 & .074 & .495 \\
\hline
\end{tabular}

B, coefficient for the constant; S.E., standard error around the coefficient for the constant; Wald, Wald chi-square test; Sig, significance (significant if $p<0.05$ ); df, degrees of freedom; $\operatorname{Exp}(B)$ : exponentiation of the $B$ coefficient. 
a doctor when hearing a negative comment about vaccines. Similarly, being aware of any influential group/leaders that advocate for anti-vaccination and being influenced by historical events were not associated with hesitancy among parents. Trust in $\mathrm{MOH}$ regarding health policies was found to be a highly significant factor, with those answering negatively being ten-times more likely to be hesitant (OR 10.23, $p<0.001,95 \%$ CI 3.464-30.197). There was also an association with $\mathrm{VH}$ and negative responses to questions regarding trust in pharmaceutical industries (OR 10.29, $\mathrm{p}<0.001$, 95\%CI 4.322-24.476) and geographical barriers to vaccination (OR 4.42, $\mathrm{p}=0.002,95 \%$ CI 1.736-11.251).

Giving a negative responses to WHO individual/group influence questions was found to be associated with hesitant behavior among parents.

In terms of vaccine/vaccination specific issues, being apprehensive towards new vaccines (OR 8.387, p - 0.001, 95\%CI 2.45228.686 ) or the design of vaccines and the procedure (OR 10.81, $\mathrm{p}<0.001,95 \%$ CI $3.827-30.547$ ) resulted in being approximately 10 times more likely to be VH. Having issues with vaccination schedule (OR 2.684, $\mathrm{p}=0.017,95 \% \mathrm{CI} 1.190-6.051)$, cost of vaccines (OR 3.347, $\mathrm{p}=0.003,95 \%$ CI 1.511-7.418), scientific evidence regarding the risk and benefit of vaccines (OR 18.26, $\mathrm{p}<0.001,95 \%$ CI 4.412-75.580) was also associated with $\mathrm{VH}$.

\section{Multivariate analysis predicting $\mathrm{VH}$ among parents}

A multivariate (stepwise) binary logistic regression analysis was undertaken to assess the relationship between demographic and WHO determinants as predictors of $\mathrm{VH}$ among parents. Following stepwise regression using the forward conditional model, the full model containing the five remaining predictors (male gender, distrust of the pharmaceutical industry, distrust of the health system/providers, negative past experiences of vaccinations and reluctance to be the first recipient for new vaccines) were statistically significant in predicting the incidence of $\mathrm{VH}$. The model explained between 29.8\% (Cox \& Snell R square) and $53.0 \%$ (Nagelkerke R square) of the variance in VH among parents and correctly classified $85.6 \%$ of cases.

As shown in Table 8, the five independent variables made a unique statistically significant contribution to the model. The strongest predictor of $\mathrm{VH}$ was reluctance to be the first recipient for new vaccines (OR: 25.00, $p=0.001$, 95\% CI 3.571-166.67), followed by negative past experiences of vaccinations (OR: 8.214, $p=0.004$, 95\% CI 1.991-33.879), distrust of the health system/providers (OR: 6.173, $p=0.003,95 \%$ CI 1.835-20.833), being a male parent (OR: 4.608, $p=0.009$, 95\% CI: $1.477-$ 14.493) and distrust of the pharmaceutical industry (OR: 2.431, $p<0.001,95 \%$ CI 1.135-5.204).

\section{Discussion}

\section{Prevalence of $\mathrm{VH}$ among parents}

Our study discovered a prevalence of VHPs of $14.5 \%$. This was higher than the figure of $11.6 \%$ as discovered by Azizi and collaborators ${ }^{54}$. This rate might translate to a poorer uptake of vaccines in the future ${ }^{55}$.

In Malaysia, Ezat discovered that $12.9 \%$ of respondents did not accept HPV vaccination for their daughters. However, this study was conducted among mothers only, rather than parents of both genders ${ }^{56}$. In a recent survey, the National Health and Morbidity Survey $2016^{57}$, it was revealed that only $86.4 \%$ of children in Malaysia has complete immunization coverage. This is still considered unsatisfactory. Overall, these studies show a trend of $\mathrm{VH}$ behavior among $10-15 \%$ of parents in Malaysia.

However, Eve Dubé has recorded a high prevalence rate of $30 \%$ in her multi-country study on $\mathrm{VH}^{58}$. Although the prevalence levels found here in Malaysia are lower, we cannot tell if the problem will continue growing rampantly. Necessary actions should be taken to curb this behavior before it becomes a bigger problem for outbreaks of VPDs in the future. It has been said that "vaccination is a victim of its own success" ${ }^{17}$, considering the fact that vaccination programs have been so successful and that VPDs are becoming less visible; therefore, people are now focused on the risk and alleged risk of vaccines, rather than the risk of contracting the diseases they protect us from.

\section{Determinants of $\mathrm{VH}$}

Introduction to a new vaccine. Introduction to a new vaccine was the strongest predictor of $\mathrm{VH}$ among parents. More than half would not agree to be the first to vaccinate their child when a new vaccine was released. In the past, when the HPV

Table 8. Multivariate binary logistic regression predicting likelihood of vaccine hesitancy among 221 parents.

\begin{tabular}{|l|l|l|l|l|l|l|l|l|}
\hline Variables in the equation & & \multicolumn{3}{c|}{$95 \%$ CI for Exp (B) } \\
\hline Predictors & B & S.E. & Wald & df & Sig. & Exp (B) & Lower & Upper \\
\hline Reluctance to be the first recipient for new vaccine & -3.222 & 0.994 & 10.511 & 1 & 0.001 & 25.00 & 3.571 & 166.67 \\
\hline Past bad experiences on vaccinations & 2.106 & 0.723 & 8.484 & 1 & 0.004 & 8.214 & 1.991 & 33.879 \\
\hline No trust in pharmaceutical industries & -2.127 & 0.597 & 12.705 & 1 & 0.000 & 2.431 & 1.135 & 5.204 \\
\hline No trust in health system and provider & -1.822 & 0.620 & 8.628 & 1 & 0.003 & 6.173 & 1.835 & 20.833 \\
\hline Male gender & -1.528 & 0.581 & 6.922 & 1 & 0.009 & 4.608 & 1.477 & 14.493 \\
\hline
\end{tabular}

B, coefficient for the constant; S.E., standard error around the coefficient for the constant; Wald, Wald chi-square test; Sig, significance (significant if $\mathrm{p}<0.05)$; df, degrees of freedom; $\operatorname{Exp}(B)$ : exponentiation of the B coefficient. 
vaccination was newly released, there was poor uptake of the vaccine as it was done on a voluntary basis, rather than being subsidized and compulsory as part of the national immunization schedule. Logistically, new vaccines are more expensive to manufacture and hence, the element of cost may be a reason for this poor uptake.

Safety and efficacy might be another reason for this, with at least $40-50 \%$ of parents reporting concern in regard to this. This same phenomenon was observed when the H1NI vaccine was introduced in 2009. There was a very low uptake rate of H1NI vaccine, which was mainly attributed to concerns about the safety of what was perceived to be a newly developed $\operatorname{drug}^{59}$. We see a similar trend in Malaysia. Despite having approximately two million cases of people infected with dengue per year ${ }^{60}$, the introduction of a new vaccine, which was approved in Mexico in 2015 , is still stalled due to safety fears. The idea of waiting for the perfect vaccine concoction with high efficacy and satisfactory safety profile may be one of the reasons for VHPs. Unless a new vaccine is proven to be safe in the long-term, this factor remains to be the most important in determining the confidence of parents in vaccines.

Negative past experiences. While the quality of vaccination services might have a positive influence on vaccine acceptance, negative past experiences of vaccination or vaccination services can also affect the acceptance of vaccination. Nowak and Cacciatore $^{61}$ have shown that personal experience of bad or adverse events following vaccination correlates with the lower confidence levels. They have also shown that confidence levels were higher in parents who did not have a child who experienced any bad reactions or did not know of anyone who had. Similarly, stories about vaccine adverse events, including those reported by the media, would affect the confidence levels of parents regarding vaccination.

We therefore would suggest that special attention should be given to this finding. Medical practitioners and healthcare workers should always be aware that any experience of the parents and also those indirectly acquired from others might influence their confidence level. They perhaps should interview the parents in order to learn about their experiences and then make an extra effort to explain the misconceptions and provide the information on how rarely these complications occur.

It has been shown that anti-vaccine activists have been spreading fears about vaccination, especially about the safety of vaccines. The fear about the MMR vaccine casing autism is still being spread widely in our community and this secondary 'experience' might have an impact on parents. Although there is little data on the correlation between anti-vaccine websites and decision-making by parents regarding vaccination, it is alarming to know that studies have shown that parents who delayed or refused vaccines are most likely to be those who have sought knowledge regarding vaccines on the internet ${ }^{62}$.
Trust in the pharmaceutical industry. The main reason for the lack of trust in the pharmaceutical industry may be due to the social stigma that pharmaceutical companies are profit-driven and do not care about the safety and efficacy of their products. We have seen an all-time low level of trust in large pharmaceutical companies that manufacture and promote vaccines. This fear of what is known as 'pharmaceutical-industrial complex' has led some parents to believe that there is a conspiracy in the vaccine industry ${ }^{63}$. These parents argued that the results of vaccination research are influenced by pharmaceutical lobbying influences ${ }^{64}$.

Other possible reasons include the use of foreign products such as thimerosal, albumin or aluminum-based additives. Being unsure of the reliability and possible harmful effects of these constituents may play a role in the $\mathrm{VH}$ of parents ${ }^{27}$. In addition, porcine constituents are one of the major concerns for many, as it is against the 'Halal' principle in the Islam religion, followed the majority of our participants ${ }^{65}$. There is a misguided belief that vaccines contain porcine DNA, hence making them impure and forbidden for use by Muslims ${ }^{54}$.

Trust in the health system and provider. The term 'trust' has an array of meanings in the medical literature. To put it simply in the context of vaccine and vaccination, it is about making a risk versus benefit decision when someone has incomplete or inadequate information ${ }^{66}$. A few studies have shown that $\mathrm{VH}$ is closely related to the idea of trust in health professionals and health providers, including the health system and health institutions ${ }^{67,68}$. Trust in the health system and health providers, who recommend the use of vaccines and determine the vaccination schedules, has a heavy bearing on the development of $\mathrm{VH}$ among parents ${ }^{59}$.

Benin et $a l .{ }^{20}$ noticed that trust, or the lack of it, forms the basis for parents to either vaccinate or not vaccinate their children, while Larson et al. have pointed out that trust placed in the healthcare system, in the healthcare workers, and also in the policy makers who decide on the vaccination programs, mediates the impact of these factors on vaccine hesitancy ${ }^{17}$. It is also interesting to note that the level of trust in the healthcare system is much lower among religious and ethnic minorities ${ }^{66}$. Perhaps this distrust could be traced back to way these minority groups were either neglected or discriminated against by the government that provides the healthcare system ${ }^{66}$. This is a possible explanation to the finding by Azizi et al. ${ }^{54}$ that non-Muslims in Malaysia were more vaccine hesitant than Muslims, since they were in the minority of the population in this country and felt they were being discriminated against.

\section{Male gender}

This is a determinant which is not discussed widely in the literatures. However, Siddiqui et al. ${ }^{69}$ found that there was noticeable gender differences among parents. In their study, women were shown to have more trust than men in vaccines. We 
have also seen that research on barriers to vaccination rarely records the views of men and families related to vaccination ${ }^{70}$. However, women and social and familial status play a very crucial role in facilitating the process of vaccination.

It is almost a global phenomenon that men or fathers are rarely involved in vaccination programs by the government. Therefore, information regarding vaccines or VPDs normally does not reach them ${ }^{71}$. By targeting only women, vaccination interventions somehow neglect the influence of men as head of the family in Asian culture in general, and in Malaysian culture in particular. Due to this lack of exposure to information on vaccines and VPDs, men may be more susceptible to the kinds of influences discussed above and subsequently have a bearing on women's decisions about vaccination as well. This, to us, is the only probable cause for this $\mathrm{VH}$ among men due to being neglected in education programs regarding vaccination.

\section{Implications/future direction}

Our study is one of the first few studies to explore the WHO determinants and $\mathrm{VH}$ among parents. In addition to the recent literature in this field, our study allows for a better understanding of $\mathrm{VH}$ behavior in Malaysia. The findings of this study are hoped to help transparency and awareness, which is important in gaining trust and guiding parents' decisions on childhood vaccination. Pharmaceutical companies should work together with government healthcare bodies for the primary prevention of VH behavior in parents. For example, this can be done through health campaigns or health talks for parents in schools, or even through mass media for easier accessibility. Doubts, concerns, misconceptions and new healthcare policies and vaccines should be addressed publicly. Information sources should be made available on online platforms, as an easy reference for parents.

Parental decisions are mainly influenced by doctors. Hence it is crucial that doctors can answer patients' questions regarding vaccines. When faced with doubts or concerns, they should be well equipped with sufficient evidence from multiple sources to justify the need for vaccines in children and provide relevant information upon the request of parents. Regular Continuous Medical Education (CME) sessions should be given to keep doctors up to date on recent literature on vaccines. $\mathrm{MOH}$ healthcare facilities should encourage and seek feedback from patients, including about confidence and trust in $\mathrm{MOH}$ itself. An audit should be done annually to identify any specific issues or concerns, which should be attended to in an appropriate and timely manner.

\section{Limitations of the study}

There are certain limitations to our study to be recognized. First, the study design precludes the possibility of causality between the factors tested with $\mathrm{VH}$. The findings from the study are also based on the self-perception of the parent at one particular time. This could potentially change over time, place and context. As the participants were given a choice of whether to answer each question, there was several missing values which could not be accounted for in our study. It is unsure if this is due to a lack of understanding of any of the questions or any other specific reasons. The study could not account for other potentially significant predictors of $\mathrm{VH}$ because the independent risk factors in the model could only explain $29.8 \% \%$ to $53.0 \% \%$ of the variance in $\mathrm{VH}$. Further studies should explore other factors that may be related to VHPs in a multi-ethnic country, such as an association of cultural or social differences with $\mathrm{VH}$ in parents. A qualitative research design may be necessary to explore this gap of knowledge in our diverse community setting.

Selection bias was also seen, as participants were included only if they could read and understand Malay or English Language. This may affect the findings as it excluded other languages spoken in Malaysia, such as Mandarin and Tamil. When looking at number of children, mothers pregnant with their first child and their spouses were excluded, as this section was filled with zero. Using convenience sampling to recruit our patients resulted in a highly skewed ethnic and religious population, where nearly $90 \%$ consisted of Malays and Muslims. This is not reflective of the overall Malaysian population; hence, the findings cannot be generalized to all Malaysian parents. Ideally, these factors should be taken into consideration using a simple random sampling method to recruit participants to achieve a more accurate population that can be generalized to all Malaysian parents.

Finally, this study is based in a single center in an urban area of Kuala Lumpur. The responses and the results might be different in a semi-urban or rural population.

\section{Conclusion}

To summarize, the prevalence of $\mathrm{VH}$ is reported at $14.5 \%$ in parents in Kuala Lumpur, Malaysia. The main determinants described by WHO SAGE working group were studied in this population and five factors were identified as significant predictors of $\mathrm{VH}$ : namely, reluctant to be the first recipient of a new vaccine, negative past experiences, distrust in the pharmaceutical industry, distrust in the health system and provider, and of male gender. These factors must be recognized and studied further to identify any temporal relationship to under-immunization in children. Equipped with this, hopefully we can play our part in reaching the WHO goal of $100 \%$ immunization coverage in children and the eradication of VPDs.

\section{Data availability}

\section{Underlying data}

Harvard Dataverse: Replication Data for: Vaccine hesitancy among parents in Kuala Lumpur: a single center study. https://doi. org/10.7910/DVN/BU5HGV51.

This project contains the following underlying data:

- Vaccine Hesitancy Raw Data.tab (demographic information and questionnaire responses for each participant)

- $\quad$ Vaccine Hesitancy OUTPUT.pdf (raw statistical analysis output data) 


\section{Extended data}

Harvard Dataverse: Replication Data for: Vaccine hesitancy among parents in Kuala Lumpur: a single center study. https://doi. org/10.7910/DVN/BU5HGV 5 .

This project contains the following extended data:

- $\quad$ PIS \& Consent Form (ENGLISH).pdf

- $\quad$ PIS \& Consent Form (MALAY).pdf
- Questionnaire Proforma - Vaccine Hesitancy (ENGLISH).pdf

- Questionnaire Proforma - Vaccine Hesitancy (MALAY).pdf

Data are available under the terms of the Creative Commons Zero "No rights reserved" data waiver (CCO 1.0 Public domain dedication)
1. The History of Vaccines: The College of Physicians of Philadelphia. Reference Source

2. Yaqub O, Castle-Clarke S, Sevdalis N, et al:: Attitudes to vaccination: A critical review. Soc Sci Med. 2014; 112: 1-11.

PubMed Abstract | Publisher Full Text

3. Andre FE, Booy R, Bock HL, et al.: Vaccination greatly reduces disease, disability, death and inequity worldwide. Bull World Health Organ. 2008; 86(2): $140-6$.

PubMed Abstract | Publisher Full Text | Free Full Text

4. Ferriman $A: B M J$ readers choose the "sanitary revolution" as greatest medical advance since 1840. BMJ. 2007; 334(7585): 111 Publisher Full Text | Free Full Text

5. Jacobson RM, St Sauver JL, Finney Rutten LJ: Vaccine hesitancy. Mayo Clin Proc. (CONCISE REVIEW FOR CLINICIANS) (Report). 2015; 90(11): 1562-1568. PubMed Abstract | Publisher Full Text

6. Hackett AJ: Risk, its perception and the media: the MMR controversy. Community Pract. (PROFESSIONAL). 2008; 81(7): 22-5. PubMed Abstract

7. Immunization coverage. World Health Organization; 2017. Reference Source

8. The State Of Asia-Pacific's Children. Nairobi, Kenya: UNICEF; 2008. Reference Source

9. MacDonald NE; SAGE Working Group on Vaccine Hesitancy: Vaccine hesitancy: Definition, scope and determinants. Vaccine. 2015; 33(34): 4161-4. PubMed Abstract | Publisher Full Text

10. Heidi Larson EK: Rapid literature review on motivating hesitant population groups in Europe to vaccinate. 1 ed. Stockholm: ECDC - European Centre for Disease Prevention and Control; 2015.

11. Stefanoff $\mathrm{P}$, Mamelund SE, Robinson M, et al.: Tracking parental attitudes on vaccination across European countries: The Vaccine Safety, Attitudes, Training and Communication Project (VACSATC). Vaccine. 2010; 28(35): 5731-7. PubMed Abstract | Publisher Full Text

12. Sadovnick $A D$, Scheifele $D W$ : School-based hepatitis $B$ vaccination programme and adolescent multiple sclerosis. Lancet. 2000; 355(9203): 549-50. PubMed Abstract | Publisher Full Text

13. Monteyne $P$, André $F E$ : Is there a causal link between hepatitis $B$ vaccination and multiple sclerosis? Vaccine. 2000; 18(19): 1994-2001. PubMed Abstract | Publisher Full Text

14. Ascherio A, Zhang SM, Hernán MA, et al.: Hepatitis B vaccination and the risk of multiple sclerosis. N Engl J Med. 2001; 344(5): 327-32. PubMed Abstract | Publisher Full Text

15. Mikaeloff $\mathrm{Y}$, Caridade $\mathrm{G}$, Rossier M, et al: Hepatitis $\mathrm{B}$ vaccination and the risk of childhood-onset multiple sclerosis. Arch Pediatr Adolesc Med. 2007; 161(12): 1176-82.

PubMed Abstract | Publisher Full Text

16. Verger $P$, Fressard L, Collange $F$, et al: Vaccine Hesitancy Among General Practitioners and Its Determinants During Controversies: A National Crosssectional Survey in France. EBioMedicine. 2015; 2(8): 891-7. PubMed Abstract | Publisher Full Text | Free Full Text

17. Larson $\mathrm{HJ}$, Cooper LZ, Eskola J, et al.: Addressing the vaccine confidence gap. Lancet. 2011; 378(9790): 526-35. PubMed Abstract | Publisher Full Text

18. Salmon DA, Haber M, Gangarosa EJ, et al:: Health consequences of religious and philosophical exemptions from immunization laws: individual and societal risk of measles. JAMA. 1999; 282(1): 47-53. PubMed Abstract | Publisher Full Text

19. O'Shea T: Vaccination Is Not Immunization. 4th ed. 2015; 210. Reference Source

20. Benin AL, Wisler-Scher DJ, Colson E, et al:: Qualitative analysis of mothers' decision-making about vaccines for Infants: The Importance of Trust.
Pediatrics. 2006; 117(5): 1532-41.

PubMed Abstract | Publisher Full Text

21. Ruijs WL, Hautvast JL, van ljzendoorn G, et al.: How orthodox protestant parents decide on the vaccination of their children: a qualitative study. BMC Public Health. 2012; 12(1): 408.

PubMed Abstract | Publisher Full Text | Free Full Text

22. Woo YL, Razali SM, Chong KR, et al.: Does the success of a school-based HPV vaccine programme depend on teachers' knowledge and religion? - A survey in a multicultural society. Asian Pac J Cancer Prev. 2012; 13(9): 4651-4. PubMed Abstract | Publisher Full Text

23. Nordin SA, Idris F, Hamat RA, et al.: Parental refusal to diphtheria vaccine: A fatal outcome. Med J Malays. 2013; 68(5): 435-6.

PubMed Abstract

24. Kane MA: Commentary: public perception and the safety of immunization. Vaccine. 1998; 16 Suppl: S73-5. PubMed Abstract | Publisher Full Text

25. Larson $\mathrm{HJ}$, Jarrett $\mathrm{C}$, Eckersberger $\mathrm{E}$, et al:: Understanding vaccine hesitancy around vaccines and vaccination from a global perspective: A systematic review of published literature, 2007-2012. Vaccine. 2014; 32(19): 2150-9.

PubMed Abstract | Publisher Full Text

26. Opel DJ, Taylor JA, Mangione-Smith R, et al:: Validity and reliability of a survey to identify vaccine-hesitant parents. Vaccine. 2011; 29(38): 6598-605. PubMed Abstract | Publisher Full Text

27. Harmsen IA, Mollema L, Ruiter RA, et al:: Why parents refuse childhood vaccination: a qualitative study using online focus groups. BMC Public Health. 2013; 13: 1183.

PubMed Abstract | Publisher Full Text | Free Full Text

28. Butler R, MacDonald NE; SAGE Working Group on Vaccine Hesitancy: Diagnosing the determinants of vaccine hesitancy in specific subgroups: The Guide to Tailoring Immunization Programmes (TIP). Vaccine. 2015; 33(34): 4176-9. PubMed Abstract | Publisher Full Text

29. Rosenthal SL, Weiss TW, Zimet GD, et al:: Predictors of HPV vaccine uptake among women aged 19-26: Importance of a physician's recommendation. Vaccine. 2011; 29(5): 890-5.

PubMed Abstract | Publisher Full Text

30. Lyren A, Leonard E: Vaccine refusal: Issues for the primary care physician. Clin Pediatr (Phila). 2006; 45(5): 399-404. PubMed Abstract | Publisher Full Text

31. Karafillakis E, Dinca I, Apfel F, et al:: Vaccine hesitancy among healthcare workers in Europe: A qualitative study. Vaccine. 2016; 34(41): 5013-5020. PubMed Abstract | Publisher Full Text

32. Dubé E, Laberge C, Guay M, et al:: Vaccine hesitancy: An overview. Hum Vaccines Immunother. 2013; 9(8): 1763-73. PubMed Abstract | Publisher Full Text | Free Full Text

33. Nichter M: Vaccinations in the Third World: a consideration of community demand. Soc Sci Med. 1995; 41(5): 617-632. PubMed Abstract | Publisher Full Text

34. Brown K, Fraser G, Ramsay M, et al:: Attitudinal and demographic predictors of measles-mumps-rubella vaccine (MMR) uptake during the UK catch-up campaign 2008-09: cross-sectional survey. PLoS One. 2011; 6(5): e19381. PubMed Abstract | Publisher Full Text | Free Full Text

35. Quadri-Sheriff M, Hendrix KS, Downs SM, et al:: The role of herd immunity in parents' decision to vaccinate children: a systematic review. Pediatrics. 2012; 130(3): 522-530.

PubMed Abstract | Publisher Full Text

36. Brewer NT, Chapman GB, Gibbons FX, et al:: Meta-analysis of the relationship between risk perception and health behavior: the example of vaccination. Health Psychol. 2007; 26(2): 136-145. PubMed Abstract | Publisher Full Text

37. Hobson-West P: Understanding vaccination resistance: moving beyond risk. 
Health Risk Soc. 2003; 5(3): 273-283. Publisher Full Text

38. Casiday RE: Children's health and the social theory of risk: insights from the British measles, mumps and rubella (MMR) controversy. Soc Sci Med. 2007; 65(5): 1059-1070.

PubMed Abstract | Publisher Full Text

39. Serpell L, Green J: Parental decision-making in childhood vaccination. Vaccine 2006; 24(19): 4041-4046.

PubMed Abstract | Publisher Full Text

40. Wamai RG, Ayissi CA, Oduwo GO, et al:: Awareness, knowledge and beliefs about HPV, cervical cancer and HPV vaccines among nurses in Cameroon: an exploratory study. Int J Nurs Stud. 2013; 50(10): 1399-1406. PubMed Abstract | Publisher Full Text

41. Laz TH, Rahman M, Berenson AB: An update on human papillomavirus vaccine uptake among 11-17 year old girls in the United States: National Health Interview Survey, 2010. Vaccine. 2012; 30(24): 3534-40. PubMed Abstract | Publisher Full Text | Free Full Text

42. Laz TH, Rahman M, Berenson AB: Human papillomavirus vaccine uptake among 18- to 26-year-old women in the United States: National Health Interview Survey, 2010. Cancer. 2013; 119(7): 1386-92. PubMed Abstract | Publisher Full Text | Free Full Text

43. Myth and Realities: Responding to arguments against vaccination. 2013; 5: 30 PubMed Abstract | Publisher Full Text | Free Full Text

44. Freed GL, Cowan AE, Clark SJ: Primary care physician perspectives on reimbursement for childhood immunizations. Pediatrics. 2008; 122(6): 1319-24. PubMed Abstract | Publisher Full Text

45. Freed GL, Clark SJ, Cowan AE, et al:: Primary care physician perspectives on providing adult vaccines. Vaccine. 2011; 29(9): 1850-4. PubMed Abstract | Publisher Full Text

46. Neubrand TP, Breitkopf CR, Rupp R, et al.: Factors Associated With Completion of the Human Papillomavirus Vaccine Series. Clin Pediatr (Phila). 2009; 48(9): 966-9.

PubMed Abstract | Publisher Full Text

47. O'Leary ST, Allison MA, Fisher A, et al:: Characteristics of physicians who dismiss families for refusing vaccines. Pediatrics. 2015; 136(6): 1103-11. PubMed Abstract | Publisher Full Text

48. Brownlie J, Howson A: 'Between the demands of truth and government': health practitioners, trust and immunisation work. Soc Sci Med. 2006; 62(2): 433-43. PubMed Abstract | Publisher Full Text

49. Petousis-Harris H, Goodyear-Smith F, Turner N, et al:: Family physician perspectives on barriers to childhood immunisation. Vaccine. 2004; 22(17-18): 2340-4.

PubMed Abstract | Publisher Full Text

50. Goad J, Durham M: The anti-vaccine movement: A pharmacist's view. Vaccinophobia and Vaccine Controversies of the 21st Century. Springer New York; 2013; 119-28. Publisher Full Text

51. Musa AF: "Replication Data for: Vaccine hesitancy among parents in Kuala Lumpur: a single center study". Harvard Dataverse, V1, UNF: 6 : 8Nf0E+ixnR7ksxjkZhP/DQ== [fileUNF]. 2019. http://www.doi.org/10.7910/DVN/BU5HGV

52. Larson $\mathrm{HJ}$, Jarrett $\mathrm{C}$, Schulz WS, et al: Measuring vaccine hesitancy: The development of a survey tool. Vaccine. 2015; 33(34): 4165-75. PubMed Abstract | Publisher Full Text

53. Opel DJ, Magione-Smith R, Taylor JA, et al.: Development of a survey to identify vaccine-hesitant parents: the parent attitudes about childhood vaccines survey. Hum Vaccin. 2011; 7(4): 419-25. PubMed Abstract | Publisher Full Text | Free Full Text

54. Mohd Azizi FS, Kew Y, Moy FM: Vaccine hesitancy among parents in a multiethnic country, Malaysia. Vaccine. 2017; 35(22): 2955-61. PubMed Abstract | Publisher Full Text

55. Opel DJ, Taylor JA, Zhou C, et al.: The relationship between parent attitudes about childhood vaccines survey scores and future child immunization status:
A validation study. JAMA Pediatrics. 2013; 167(11): 1065-71.

PubMed Abstract | Publisher Full Text | Free Full Text

56. Ezat SW, Hod R, Mustafa J, et al.: National HPV immunisation programme: knowledge and acceptance of mothers attending an obstetrics clinic at teaching hospital, Kuala Lumpur. Asian Pac J Cancer Prev. 2013; 14(5): 2991-9. PubMed Abstract | Publisher Full Text

57. Lim KK, Chan YY, NoorAni A, et al:: Complete immunization coverage and its determinants among children in Malaysia: findings from the National Health and Morbidity Survey (NHMS) 2016. Public Health. 2017; 153: 52-57. PubMed Abstract | Publisher Full Text

58. Dubé E, Gagnon D, Nickels E, et al:: Mapping vaccine hesitancy--country-specific characteristics of a global phenomenon. Vaccine. 2014; 32(49): 6649-54.

PubMed Abstract | Publisher Full Text | Free Full Text

59. Ramanadhan S, Galarce E, Xuan Z, et al:: Addressing the Vaccine Hesitancy Continuum: An Audience Segmentation Analysis of American Adults Who Did Not Receive the 2009 H1N1 Vaccine. Vaccines. 2015; 3(3): 556-78. PubMed Abstract | Publisher Full Text | Free Full Text

60. Woon YL, Hor CP, Lee KY, et al:: Estimating dengue incidence and hospitalization in Malaysia, 2001 to 2013. BMC Public Health. 2018; 18(1): 946. PubMed Abstract | Publisher Full Text | Free Full Text

61. Nowak GJ, Cacciatore MA: Parents' confidence in recommended childhood vaccinations: Extending the assessment, expanding the context. Hum Vaccin Immunother. 2017; 13(3): 687-700.

PubMed Abstract | Publisher Full Text | Free Full Text

62. Smith PJ, Humiston SG, Marcuse EK, et al.: Parental delay or refusal of vaccine doses, childhood vaccination coverage at 24 months of age, and the Health Belief Model. Public Health Rep. 2011; 126 Suppl 2: 135-46. PubMed Abstract | Publisher Full Text | Free Full Text

63. Poland GA, Jacobson RM, Ovsyannikova IG: Trends affecting the future of vaccine development and delivery: the role of demographics, regulatory science, the anti-vaccine movement, and vaccinomics. Vaccine. 2009; 27(25-26): 3240-44.

PubMed Abstract | Publisher Full Text | Free Full Text

64. Dubé E, Vivion M, Sauvageau C, et al.: "Nature Does Things Well, Why Should We Interfere?": Vaccine Hesitancy Among Mothers. Qual Health Res. 2016; 26(3): 411-25 PubMed Abstract | Publisher Full Text

65. Jeyachelvi K, Juwita S, Norwati D: Human Papillomavirus Infection and its Vaccines: Knowledge and Attitudes of Primary Health Clinic Nurses in Kelantan, Malaysia. Asian Pac J Cancer Prev. 2016; 17(8): 3983-8. PubMed Abstract

66. Larson HJ, Clarke RM, Jarett C, et al:: Measuring trust in vaccination: A systematic review. Hum Vaccin Immunother. 2018; 14(7): 1599-09. PubMed Abstract | Publisher Full Text | Free Full Text

67. Streefland $P$, Chowdhury AMR, Ramos-Jimenez P: Patterns of vaccination acceptance. Soc Sci Med. 1999; 49(12): 1705-16. PubMed Abstract | Publisher Full Text

68. Hobson-West P: 'Trusting blindly can be the biggest risk of all': organised resistance to childhood vaccination in the UK. Sociol Health IIIn. 2007; 29(2): 198-15.

PubMed Abstract | Publisher Full Text

69. Siddiqui M, Salmon DA, Omer SB: Epidemiology of vaccine hesitancy in the United States. Hum Vaccin Immunother. 2013; (12): 2043-8. PubMed Abstract | Publisher Full Text | Free Full Text

70. Coreil J, Losikoff $\mathrm{P}$, Pincu $\mathrm{R}$, et al: Cultural feasibility studies in preparation fo clinical trials to reduce maternal-infant HIV transmission in Haiti. AIDS Educ Prev. 1998; 10(1): 46-62. PubMed Abstract

71. Sen G, Östlin P, George A: Unequal, Unfair, Ineffective and Inefficient. Gender Inequity in Health: Why it exists and how we can change it. Final report to the WHO Commission on Social Determinants of Health, WHO; 2007. Reference Source 


\section{Open Peer Review}

\section{Current Peer Review Status: $\mathrm{X}$ ?}

\section{Version 1}

Reviewer Report 26 August 2020

https://doi.org/10.5256/f1000research.22046.r64442

(C) 2020 Aggarwal A. This is an open access peer review report distributed under the terms of the Creative Commons Attribution License, which permits unrestricted use, distribution, and reproduction in any medium, provided the original work is properly cited.

\section{Anju Aggarwal}

Department of Pediatrics, University College of Medical Sciences and Guru Tegh Bahadur Hospital, New Delhi, India

This is a good study.

Introduction seems to be too long as if a combination of review and a study.

Introduction does not need a illustration from another study or book.

Sample size has been calculated and ethical clearance has been obtained. The article can be indexed after modification.

A separate review article could be created.

Is the work clearly and accurately presented and does it cite the current literature? Yes

Is the study design appropriate and is the work technically sound?

Yes

Are sufficient details of methods and analysis provided to allow replication by others? Yes

If applicable, is the statistical analysis and its interpretation appropriate? Yes

Are all the source data underlying the results available to ensure full reproducibility? Yes

Are the conclusions drawn adequately supported by the results? 
Yes

Competing Interests: No competing interests were disclosed.

Reviewer Expertise: child neurology and immunization

I confirm that I have read this submission and believe that I have an appropriate level of expertise to confirm that it is of an acceptable scientific standard, however I have significant reservations, as outlined above.

Reviewer Report 26 August 2020

https://doi.org/10.5256/f1000research.22046.r64443

(C) 2020 Succi R. This is an open access peer review report distributed under the terms of the Creative Commons Attribution License, which permits unrestricted use, distribution, and reproduction in any medium, provided the original work is properly cited.

\section{Regina Célia de Menezes Succi}

Department of Pediatrics, Universidade Federal de São Paulo (UNIFESP), São Paulo, Brazil

The manuscript from Ahmad Farouk Musa and colleagues has the objective of improving the understanding of vaccine hesitancy among parents in Kuala Lumpur, by determining the prevalence of $\mathrm{VH}$ and identify predictors associated with this attitude. The results are interesting to this region, but some questions should be addressed.

1. The Introduction contains more information than needed. It should be shorter and more objective.

2. There are too much Tables and Figures with similar data. All the figures should be excluded.

Is the work clearly and accurately presented and does it cite the current literature? Yes

Is the study design appropriate and is the work technically sound?

Yes

Are sufficient details of methods and analysis provided to allow replication by others? Yes

If applicable, is the statistical analysis and its interpretation appropriate? Yes

Are all the source data underlying the results available to ensure full reproducibility? Yes

Are the conclusions drawn adequately supported by the results? 
Yes

Competing Interests: No competing interests were disclosed.

Reviewer Expertise: Pediatric Infectious Diseases, Vaccines, HIV

I confirm that I have read this submission and believe that I have an appropriate level of expertise to confirm that it is of an acceptable scientific standard, however I have significant reservations, as outlined above.

Reviewer Report 02 June 2020

https://doi.org/10.5256/f1000research.22046.r54109

(C) 2020 Angelillo I. This is an open access peer review report distributed under the terms of the Creative Commons Attribution License, which permits unrestricted use, distribution, and reproduction in any medium, provided the original work is properly cited.

\section{Italo Francesco Angelillo}

Department of Experimental Medicine, University of Campania "Luigi Vanvitelli", Naples, Italy

The aims of the study were to understand vaccine hesitancy among parents in Kuala Lumpur, Malaysia, by determining the prevalence of $\mathrm{VH}$ among parents and to identify the predictors associated with a vaccine hesitant attitude. Substantial revisions are necessary to be addressed. The paper also needs editing by a native English person.

\section{Introduction}

1. The introduction is too long and should be considerably condensed.

\section{Methods}

1. It is not indicated how many Health Community Clinic are present in the geographic area. Please clarify.

2. It is not given any information regarding a pilot study for testing the survey questionnaire. Please clarify.

3. It should be indicated who and how many investigators approached the sample. Please clarify.

4. The Authors should clarify about the face-validity testing of the questions with an explanation of the validity of the content of the questions with regard to the research aims.

5. The Authors should clarify if the questionnaire was anonymous and no personally identifiable information was collected.

6. The Authors should clarify whether the participants have received any gift or monetarily compensated. 
7. One of the major methodological weakness is that the sample size calculation indicated that 275 was the target size and a total of 380 questionnaires were distributed. However, when parents with at least one child were included the giving sample size was only 221 . Since one of the aims of the study was to determine the prevalence of Vaccine hesitancy among parents, it is not clear why the selection was not restricted only to parents.

8. The statistical analysis is not, strictly speaking, adequate, because it would be particularly relevant to describe the model developed, the variables included, and the rationale why they are included. Moreover, it should be indicated if the statistical tests were one-side or two-sides. It would be particularly relevant to include in the model the source of information.

\section{Results}

1. No information is given about how many individuals refused to participate and the response rate should be included. If not all patients have agreed to participate, no information is given about them. Was there any attempt to quantify the response bias: information about non-responders. It would be useful to have some kind of indication of comparability with non-respondents. Is there any population-based data available? How did they differ from those in the sample, how representative is the sample and were the findings representative?

2. The characteristics of the sample should be considerably condensed.

3. The results of the ORs and of the $95 \%$ CI should be with only two decimals.

\section{Discussion}

1. It should be inserted a deeper comment regarding the results of previous surveys conducted in different geographic areas on vaccine hesitancy. The following articles should be cited: Dubè Human Vaccines \& Immunotherapeutics 2019;15(1):113-120 ${ }^{1}$. Napolitano et al. Human Vaccines \& Immunotherapeutics 2018;14:1558-1565) ${ }^{2}$.

2. Page 16: It is stated that Trust in the health system and health providers, who recommend the use of vaccines and determine the vaccination schedules, has a heavy bearing on the development of $\mathrm{VH}$ among parents. The role of health professionals is vital and additional references regarding other studies in order to support the statement should be added. Cite: D'Alessandro et al. Hum Vaccin Immunother 2018;14:1573-93; Ragan et al. Vaccine 2018;36:331-414; Napolitano et al. Hum Vaccin Immunother 2016;12:1504-105.

3. The paragraph regarding the main limitations of the study should discuss all limits such as, for example, the recall bias and the social desirability bias.

\section{Figures and Tables}

1. Tables 7 and 8 should be condensed and should report only the OR (with only two decimals), the S.E., the $95 \%$ CI (with only two decimals), and the p-value.

2. Figures 1 to 6 should be deleted.

3. Table 5 should be deleted. 


\section{References}

1. Dubé È, Farrands A, Lemaitre T, Boulianne N, et al.: Overview of knowledge, attitudes, beliefs, vaccine hesitancy and vaccine acceptance among mothers of infants in Quebec, Canada.Hum Vaccin Immunother. 2019; 15 (1): 113-120 PubMed Abstract | Publisher Full Text

2. Napolitano F, D'Alessandro A, Angelillo I: Investigating Italian parents' vaccine hesitancy: A cross-sectional survey. Human Vaccines \& Immunotherapeutics. 2018; 14 (7): 1558-1565 Publisher

Full Text

3. D'Alessandro A, Napolitano F, D'Ambrosio A, Angelillo I: Vaccination knowledge and acceptability among pregnant women in Italy. Human Vaccines \& Immunotherapeutics. 2018; 14 (7): 1573-1579 Publisher Full Text

4. Ragan K, Bednarczyk R, Butler S, Omer S: Missed opportunities for catch-up human papillomavirus vaccination among university undergraduates: Identifying health decision-making behaviors and uptake barriers. Vaccine. 2018; 36 (2): 331-341 Publisher Full Text 5. Napolitano F, Napolitano P, Liguori G, Angelillo I: Human papillomavirus infection and vaccination: Knowledge and attitudes among young males in Italy. Human Vaccines \& Immunotherapeutics. 2016; 12 (6): 1504-1510 Publisher Full Text

Is the work clearly and accurately presented and does it cite the current literature? Partly

Is the study design appropriate and is the work technically sound?

Partly

Are sufficient details of methods and analysis provided to allow replication by others? Yes

If applicable, is the statistical analysis and its interpretation appropriate? Partly

Are all the source data underlying the results available to ensure full reproducibility? No

Are the conclusions drawn adequately supported by the results? Yes

Competing Interests: No competing interests were disclosed.

Reviewer Expertise: Public Health

I confirm that I have read this submission and believe that I have an appropriate level of expertise to state that I do not consider it to be of an acceptable scientific standard, for reasons outlined above. 
The benefits of publishing with F1000Research:

- Your article is published within days, with no editorial bias

- You can publish traditional articles, null/negative results, case reports, data notes and more

- The peer review process is transparent and collaborative

- Your article is indexed in PubMed after passing peer review

- Dedicated customer support at every stage

For pre-submission enquiries, contact research@f1000.com 